Portland State University

PDXScholar

11-18-1994

\title{
An Improved English Article System for Japanese Speakers
}

Dorothy Jean Frew

Portland State University

Follow this and additional works at: https://pdxscholar.library.pdx.edu/open_access_etds

Part of the Bilingual, Multilingual, and Multicultural Education Commons Let us know how access to this document benefits you.

\section{Recommended Citation}

Frew, Dorothy Jean, "An Improved English Article System for Japanese Speakers" (1994). Dissertations and Theses. Paper 5020.

https://doi.org/10.15760/etd. 6896

This Thesis is brought to you for free and open access. It has been accepted for inclusion in Dissertations and Theses by an authorized administrator of PDXScholar. Please contact us if we can make this document more accessible: pdxscholar@pdx.edu. 


\section{THESIS APPROVAL}

The abstract and thesis of Dorothy Jean Frew for the Master of Arts degree in Teaching English to Speakers of Other Languages were presented November 18, 1994 and accepted by the thesis committee and the department

COMMITTEE APPROVALS:

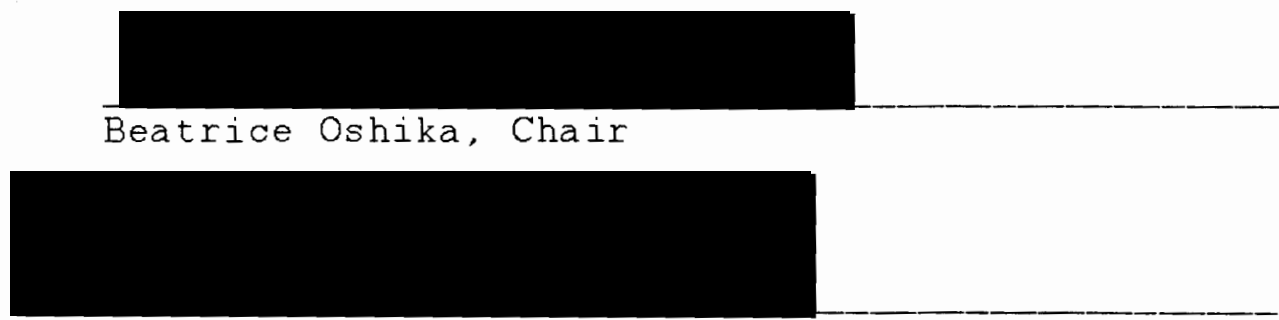

Thomas G. Dieterich

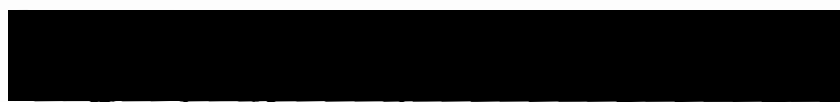

Suwako Watanabe

Representative of the Office of Graduate Studies

DEPARTMENT APPROVAL

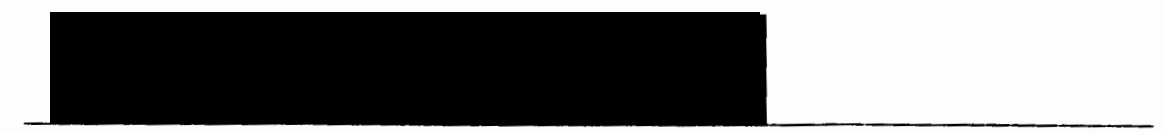

Beatrice Oshika, Chair

Department of Applied Linguistics

ACCEPTED FOR PORTLAND STATE UNIVERSITY BY THE LIBRARY

by on 27 Eekentert 1995 
ABSTRACT

An abstract of the thesis of Dorothy Jean Frew for the Master of Arts in Teaching English to Speakers of Other Languages presented November 18, 1994

Title: An Improved English Article System for Japanese Speakers

One aspect of the English language which has been overlooked by English-as-a-Second-Language educators is the article system, $a$, the, and $\theta$. For students from articleless first languages such as Japanese, learning this complex system is a formidable challenge. Performance studies show an error rate among advanced Japanese students of approximately thirty percent. There may be several reasons for this high rate: 1) the differences between Japanese and English, 2) the unusually high degree of complexity/difficulty of the article system itself compared to other English morpheme systems and 3) inadequate treatments of the subject as revealed in this thesis' survey of forty ESL textbooks. 
Recent pragmatic discoveries about article function reveal subtle, contextual influences which have not been well integrated into traditional treatments. Definiteness may be dependent on sentential, discourse, and situational contexts, on whether referents are unique and manifest to the hearer, and on the nature of certain implicatures induced by the articles. Computerized, interactive tutorials are the best way to capture how these variables interact to constrain article choice.

A prototype for a tutorial is submitted with this thesis. In addition to exhaustive explanations of contexts and implicatures in the form of actor's "asides," it features Japanese translations throughout, and, to show how uniqueness may be culture bound, utterances that take place within Japanese culture. Although the tutorial presented here needs enlargement, it is believed that an animated, computerized tutorial emphasizing subtle pragmatic features is more illustrative of actual article usage than have been traditional hard copy explanations. 


\title{
AN IMPROVED ENGLISH ARTICLE SYSTEM \\ FOR JAPANESE SPEAKERS
}

\author{
by \\ DOROTHY JEAN FREW
}
A thesis submitted in partial fulfillment of the requirements for the degree of
MASTER OF ARTS
in
TEACHING ENGLISH TO SPEAKERS OF OTHER LANGUAGES

\author{
Portland State University \\ 1995
}




\section{ACKNOWLEDGEMENTS}

Many people have helped bring this project to its

final form. I would like to thank:

Professor Beatrice oshika for her intelligence, enthusiasm, and humor.

Professor Thomas Dieterich, whose high standards of disciplined argumentation sustained my interest in Iinguistics throughout the master's program.

Professor Suwako Watanabe for comparing the Japanese use of the articles to a game of chance.

Ron Rasch for his delightful illustrations.

Noriko Iwasaki for her 1991 thesis and its

illuminating discussion of the problems the articles present to Japanese speakers.

Yasuhiro Misaki, whose long, eloquent discussions on Japanese culture fascinated me yet also taxed me mentally because they were completely article free. I soon learned that English without articles gave me a headache, and in this painful way I discovered that the three little words do matter after all. 
TABLE OF CONTENTS

PAGE

ACKNOWLEDGEMENTS $\ldots \ldots \ldots \ldots \ldots \ldots \ldots \ldots \ldots \ldots \ldots \ldots \ldots \ldots \ldots \ldots \ldots$

LIST OF TABLES $\ldots \ldots \ldots \ldots \ldots \ldots \ldots \ldots \ldots \ldots \ldots \ldots \ldots \ldots \ldots \ldots \ldots$

LIST OF FIGURES............................ CHAPTER

I INTRODUCTION $\ldots \ldots \ldots \ldots \ldots \ldots \ldots \ldots \ldots \ldots \ldots \ldots \ldots$

II DESCRIPTION OF THE PROBLEM $\ldots \ldots \ldots \ldots \ldots \ldots \ldots$

Do Errors Really Matter...............

Error Rate Among Japanese Students ....6

Importance to English Speakers .......7

The Learning Problem ...............10

Japanese and English Differences......10

Terminology of Definiteness .....15

Expressing Definiteness Overtly ..16

Markedness .............. 16

Performance Studies ..........17

The Count/Mass Difference ......17

Cultural Differences ..........18

Other Article-less Languages . . . . 19

Complexity of the Article System .....19

L1 Morpheme Studies..........21

L2 Morpheme Studies..........22 
Frequency to Difficulty Studies ...22 Dearth of Adequate Teaching Materials .28 First/Second Mention Fallacy .... 29 Mutual Knowledge ............. 11 Universal Uniques the moon.......33 The Numeral one $\ldots \ldots \ldots \ldots \ldots 33$ Modifiers ................... Context-less Sample Sentences . . 37 Fill-in-the-Blank Exercises .....38 Circular Definitions ..........38 Incomprehensible Explanations ...39 Limitations of Text Books ... . .39 Conclusion ...............40

III REVIEW OF THE LITERATURE $\ldots \ldots \ldots \ldots \ldots \ldots 42$ Early Philosophies .............42 Russell $1905 \ldots \ldots \ldots \ldots \ldots \ldots 42$ Strawson $1950 \ldots \ldots \ldots \ldots \ldots 44$ Jespersen $1933 \ldots \ldots \ldots \ldots$......46 Christophersen 1939 ........47 Searle 1969 ...............49 Hawkins $1978 \ldots \ldots \ldots \ldots \ldots$. . . . 50 Summary $\ldots \ldots \ldots \ldots \ldots \ldots \ldots 1$

Later Philosophies ..............52 Grice $1975 \ldots \ldots \ldots \ldots \ldots \ldots 2$ Reviews of Hawkins 1978 ........54 Declerke $1987 \ldots \ldots \ldots 55$ 
Klein $1980 \ldots \ldots \ldots 6$

Cruse $1980 \ldots \ldots \ldots 6$

Hawkins $1991 \ldots \ldots \ldots$

IV VISUALS FOR THE TUTORIAL $\ldots \ldots \ldots \ldots \ldots$

V STORY SCRIPTS FOR THE TUTORIAL............ 79

Kato and Eric Find Their Way Around Campus..80

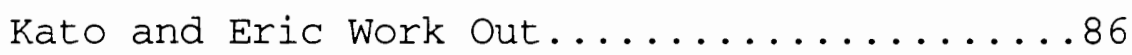

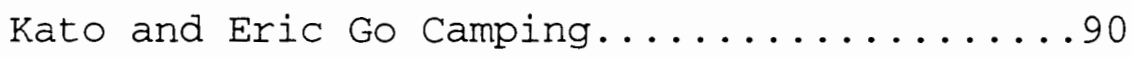

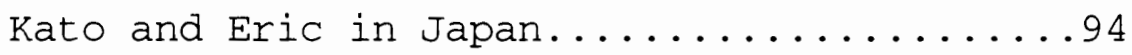

VI CONCLUSION $\ldots \ldots \ldots \ldots \ldots \ldots \ldots \ldots \ldots \ldots \ldots \ldots \ldots \ldots \ldots$

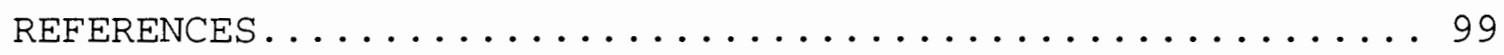

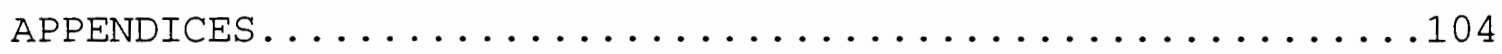

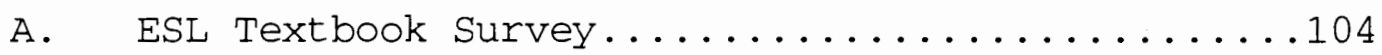

B. List of ESL Textbooks Reviewed.............113 


\section{LIST OF TABLES}

TABLE

PAGE

I First- and Second-Language Morpheme Studies.....25 
LIST OF FIGURES

FIGURE

PAGE

1. Tawa's Description of Definiteness

in Japanese $\ldots \ldots \ldots \ldots \ldots \ldots \ldots \ldots \ldots \ldots \ldots$ 
CHAPTER I

\section{INTRODUCTION}

This thesis presents suggestions for an intensive computerized tutorial on the English article system for Japanese speakers. Rational for the tutorial is provided by a high article error rate among advanced Japanese students, by acquisition research supporting a high degree of complexity of the article system, and by an underestimation of the problem by English-speaking educators. A survey of forty English-as-a-Second-Language (ESL) textbooks shows a deficiency in this area.

An examination of scholarly (i.e.,philosophical and linguistic) discussions reveals pragmatic insights that have not been well integrated into ESL materials. One such insight is that article choice is dependent on sentential, discourse, and situational contexts, and the extent to which these contexts are manifest to speaker and hearer. The present work argues that this kind of contextual information is awkward for traditional, hard copy textbooks to capture and demonstrate. Animated, interactive, computerized tutorials have the advantage of offering visually dynamic context. 
Part of this project consists of a design for such a tutorial. The materials illustrate how noun phrases are made definite by four possible pragmatic "sets" (i.e.contexts wider than a sentence) which inform hearer knowledge: 1) physical setting [of the utterance] set; 2) "linguistic" community set; 3) set resulting from bridging; and, 4) previous discourse set. Within a pragmatic set, certain linguistic structures may help to delimit the set of shared objects, namely, genitives, prepositional phrases, and restrictive relative clauses, and these too are illustrated in the materials. The materials also demonstrate how variability in interpretation of the article a derives from implicatures activated by $a$ and by whether or not the could have been used instead. This idea is a direct application of John Hawkins' 1991 implicature theory for the articles. An important aspect of the materials is that the examples, though in English, are partly situated in Japanese culture. Since mutual knowledge is key to usage, and since so much of that knowledge is culture-bound, using only American cultural settings would undermine understanding in certain cases. In fact, in the Japan-specific cases it should be impossible in this tutorial for American users to choose the correct article.

The design of this tutorial is unique in several ways. It gives intensive treatment to an area usually considered trivial; it incorporates recently discovered pragmatic 
information into its explanations, and it goes against current popular trends by making explanations available in the first language. Most importantly, it situates many examples within Japanese culture. It is claimed that the tutorial will benefit students by increasing their understanding of the systematicity behind correct article choice; it is not claimed, however, that this understanding will necessarily improve students' article proficiency. Chapter I illustrates the communication breakdowns that article errors cause and touches on three possible sources of the learning problem: 1) the differences between Japanese and English 2) the complexity of the article system and 3) the dearth of adequate instructional materials. 
CHAPTER II

\section{DESCRIPTION OF THE PROBLEM}

\section{DO ERRORS REALLY MATTER?}

Perhaps one reason educators have paid little attention to the articles is that article errors are to some extent invisible. In certain contexts, mistakes are not noticeable because either the definite article or the indefinite article sounds correct on the surface. Even though the only correct choice is the article which reflects the speaker's intended meaning, either article may seem correct to a listener because either meaning is possible in a given context. Since listeners assume that speakers mean what they say, listeners cannot detect such errors. For example,

I was disappointed in my grade, so I talked to a/the teacher about it. She told me that $a$ is respectable, so now I feel better.

$A$ and the have different referents, but because either referent is compatible with the context, a listener would have no reason to doubt a speaker's wrong choice, and the error would go unnoticed.

At other times, when errors are noticeable they seem slight because the speaker's intended meaning remains 
nonetheless clear. For example, for any NP that has inherent uniqueness (tallest building, Queen of England) the obligatory use of the, signalling uniqueness, is redundant. Thus, when a speaker omits the by mistake, the uniqueness of the referent stays intact. In *We visited tallest building in Chicago, the omission of the sounds foreign but does not damage meaning. In other unambiguous contexts, damage to meaning is slight even though $\varnothing$ is mistakenly supplied.

* We went to coast, but water was too cold for bathing.

* I live in apartment, not ondine.

* What is meaning of hunch?

These examples give the impression that articles don't count for much in actual communication. However, other examples show they do count. The poetry of the following passage from a student paper is tainted by article errors: Underneath the document he has a a picture by Sargent, the painting of Venice in watercolor. When he is tired, he stares at the painting secretly. Whenever he takes a tiny postcard with the painting out of his desk, no one notices. Its transparency washes out his stress. He feels comfortable, even in his cold, hard chair. He feels as though a light has been lit in his body. The light flicks on like a tiny fire of a match, and then glows. It happens in a brief second (Nakai 1994).

The following utterances cause communication breakdowns: 
* I was disappointed in my grade, so I talked to the teacher about it. She told me to speak to my teacher.

* I went to the class, but there were not enough chairs, so a student carried the chairs in.

(two strangers in a dormitory cafeteria)

Japanese: *I also live in dormitory.

American: Oh, on the third floor, too?

Japanese: No, fourth floor.

American: Fourth floor? I didn't know there was a fourth floor. Japanese: of course.

American: I thought just the roof was above me.

Japanese: Yes, just the roof.

American: So you live on the roof?

Japanese: Excuse me?

On hearing the unacceptable versions, a listener can make mental repairs, can request clarification, or can remain politely confused. But even listeners who see no real harm in such errors eventually find a series of them mentally draining. Worse, speakers who know they make these errors at every turn fear they can never be correct or accurate.

Empirical research shows that the problem is severe among Japanese students. Yamada and Matsuura (1982) studied an advanced group of thirty-five students at Hiroshima University who expected to become high school teachers of English after graduation. The students were found to have an article error rate of 30 percent in their writing. Since 
there are three types of articles, $a$, the, and $\varnothing$, if a student were to use them at random, the probability of accuracy would be 33.3 percent. The 30 percent error rate of the Hiroshima students is the same as a 70 percent accuracy rate, or, 36.7 percentage points better than random usage. considering the frequency of articles in English (roughly every tenth word is an article), the students' 30 percent error rate means that in a 1,000 word essay approximately 100 words would be articles, and 30 of those would be errors, or roughly 10 errors per page.

How important are articles to native speakers? One requirement for the definite article is that the noun be mutually known to speaker and hearer. Among other things, mutual knowledge may be based on community membership. Members of the same "Iinguistic" community may refer to the courthouse, the deli, the river, etc., but community also extends to any group that conjoins the knowledge bases of speaker and hearer. Clark and Marshall (1981) claim that articles are so important to English communication that "In ordinary conversation people go to some trouble to establish the communities of which they are members just so that their definite references will succeed" (p.36). This claim is illustrated in Schegloff's (1972) study of how people formulate their references to places, as when giving or receiving directions. For example, near a university a visitor would look for someone who looked like a student 
(had student membership) to ask, "Would you know where the student union is? Where Shattuck Hall is?"

Articles are important to English speakers in every type of media. Speakers may tolerate omissions in telegrams and newspaper headlines because the confusion that results is short-lived. But in extended speech or in text, frequent omissions burden the hearer's decoding process. Articles serve the purpose of clarity by providing hearers with satisfactory references. For this reason, article-less text is not a desired effect in machine translation. For example, in the Knowledge-Based Machine Translation Project (KBMT-89), devices have been built to incorporate articles into the machine-translated English output from Japanese text. According to Goodman and Nirenburg (1991), "The KBMT-89 mapping rules pick up the feature ref with values definite or indefinite and transmit it to the ILT [interlingua text] [because] information about definiteness provides important semantic information about a sentence" $(\mathrm{p} .83)$.

Part of the problem with the articles is that Englishspeaking educators have not realized that there is a problem. Being accustomed to using the same three small words so often, they tend to trivialize what the words mean and take usage for granted. Also, errors are often overlooked in the natural effort to listen for message rather than correctness of form. In everyday conversations, 
where a misunderstanding can be quickly repaired, English speakers hardly notice article errors and remain unaware of a speaker's anxiety. But article errors in text bring the reading process to a halt, aggravate the reader and, in the case of schoolwork, often result in a lower grade. One group that has not taken either speaking or writing of the articles for granted is the Japanese. They experience frustration in both modes, frustration that needs to be taken seriously. The next section will discuss some differences between Japanese and English that could partly account for the difficulty Japanese speakers experience in trying to master the English article system. 
THE LEARNING PROBLEM

Some Differences Between English and Japanese

The use of the definite article is often a source of extreme frustration for the foreign learner of English, particularly if his native language does not exhibit some overt means of expressing that which the definite article in English expresses. (Grannis 1972, p. 275)

Since Japanese is an article-less language, some believe that the concept of definiteness is foreign to Japanese speakers, a notion which Kubo (1988) and Tawa (1993) dispute. According to Kubo, "a definite NP refers to an entity that is in some sense given in the conversational common ground, whereas an indefinite NP refers to an entity that is newly added to the conversational domain." (p. 22) Both Iinguists maintain that Japanese speakers infer the definiteness status of noun phrases (NPS) and null-NPs (also called empty nouns, empty pronominals or zero anaphora), without relying on articles. Tawa illustrates her argument about null-NPs by the following example: 
[ ]i tegamij-o kakimashita ka?

[ ] letter-ACC wrote $Q \quad(A C C=$ accusative, $Q=$ interrogative) Did [you]; write the letterj?

ee kinoo [ ] $]_{i}[]_{j}$ kakimashita.

Yes yesterday [ ] [ ] wrote

Yes, [I] $]_{i}$ wrote [it]j yesterday (p. 380).

In Japanese, the full noun phrase letter becomes the nullNP [ ] j because the speaker assumes that the hearer is able to identify the referent, whereas in English the hearer would expect the pronoun it. Kubo claims that because all nuIl-NPs are anaphoric, they are inherently definite. (In English, anaphora occurs when the +definite NP refers back to a tdefinite NP previously mentioned in discourse). But Tawa argues that being anaphoric does not necessarily entail being definite. She shows how, depending on the referent, null-NPs can be interpreted as definite, indefinite or nondefinite (see Figure 1.). Nondefinite interpretations are those which allow only the most generalized, abstract knowledge of an object. She writes, "...nondefinites denote uninstantiated schemata, while definites and indefinites are instantiated forms of schemata with definites having more specifications than indefinites" (p. 383). A null-NP is interpreted as nondefinite when it refers back to a nondefinite full-NP. Her example, translated from a Japanese novel, is Does pain go away and leave no trace, 
NP or Null-NP

\section{Referential}

Nonreferential $\begin{array}{ll}\text { thearer } & \text {-hearer } \\ \text { knowledge } & \text { knowledge }\end{array}$

\section{Definite}

-...a boy comes by riding $a$ bicycle....And he sees the pears...(example from Du Bois, 1980)

-I bought a book by Tolstoy. But before 1 read it my brother tore up the book.

\section{Indefinite}

- I saw a friend in town.

- I am going to see $a$ doctor today.

\section{Indefinite}

I am thinking of buying two apples today.

-I want to marry a rich man.

-I'd like to buy an interesting book.

- It would be nice to have children. Would you like it if we adopted a child?
Nondefinite

-Does pain go away and leave no trace, then? You sometimes even feel sentimental for it.

-Books are good for children, but they can be expensive.

- He looks like a uh...Chicano American (example from Du Bois, 1980)

- Mary is a forester. She's been a forester for three years now. [Du Bois, 1980]

-

Can you swim a mile? When you can swim a mile you'll be ready for the trip. [Du Bois, 1980]

Figure 1. Tawa's description of definiteess in Japanese. 
then? You sometimes even feel sentimental for it. The Japanese null-NP that would stand in for it would carry a nondefinite interpretation because the referent pain is used in the general, abstract sense not in an instantiated sense.

Definite and indefinite interpretations must first attend to the referentiality of the referent, which must be either referential or nonreferential. These terms are not clearly defined by Tawa, but borrowing a definition from Du Bois (1980), she says that an NP is used referentially when it speaks "about an object as an object with continuous identity over time." Nonreferential NPs are "not used to speak about an object as an object" (p. 390). When the referent is both referential and "known" to the hearer, the null-NP is interpreted as definite; but when the referential referent is not known to the hearer, the null-NP is interpreted as indefinite. If the referent is nonreferential and not nondefinite, the null-NP is also interpreted as indefinite. An example of a nonreferential indefinite would be I want to marry a rich man. Here, the nonreferrential object a rich man is indefinite as opposed to nondefinite because it represents an instantiation of the abstract concept man. Presumably, if the instantiation were further specified so as to be referential and known to the listener, then it would receive a definite interpretation: I want to marry the rich man sitting at that table. 
One student's error in the Iwasaki (1990) study reflected the Japanese concept of nondefiniteness. The student wrote "...when I was high school student..." Iwasaki illuminated the error in terms of first-language (Japanese) perception. A predicate nominal like student "functions as a tool of categorization or description of attribution" (p.85). This function sounds similar to the nondefinite schema described in Tawa. Because high school student is not an instantiation of student, the subject might think of this NP as nonreferential nondefinite in Tawa's sense, similar to Mary is a forester. But, as shown in the examples, Mary is a forester and Does pain go away..., nondefinites in Japanese can be expressed with $\varnothing$ or a in English. Apparently, the student was unable to make the correct choice at this point. The examples in Figure 1., taken from Tawa, show how definiteness status in Japanese can be variously translated into the English article system.

Although Kubo and Tawa disagree about the exact status of null-NPs, they agree that Japanese hearers infer definiteness status via their perception of the noun, as informed by the context of the discourse. Though not formally encoded, definiteness status is tacitly conveyed and understood in Japanese.

Yet, it is clear that when definiteness status requires formal encoding, as it does in English, problems arise for 
the Japanese speaker. The examples in Figure 1. show that one source of difficulty may reside in the terminological confusion caused by the words definite and indefinite and what notions each controls in the two languages. (Other terms may have similar problems: specified, classified, known, unique, particular, familiar, which, reference, and identified) For example, Tawa's sense of definite could allow for either a or the in English. This sense is not at odds with how the term is used in some scholarly grammars of English but is at odds with many applied grammars and teaching grammars, wherein definite meanings are said to be rendered with the only (and indefinite meanings are said to be rendered with a only). Thus, the distinction between the definite and indefinite effects to which a noun is subject in Japanese may not correspond to the distinction said to be expressed by the choice of the article in English, and this noncorrespondence could be troublesome for students.

Beyond terminological mix-ups, Iwasaki speculates on a more serious problem. While students may grasp that a +definite NP requires both "specificity" (referentiality?) and hearer knowledge, the same general features it conveys in Japanese, students may wonder at what point these two criteria have been sufficiently met in English to warrant the definite article. That is to say, to make native-like judgements students may need a finely tuned understanding of 
the heuristics that appraise specificity and hearer knowledge, since informal definitions may be too vague. This need is implied by Yamada and Matsuura (1982): "... [students] cannot use articles correctly simply because they cannot identify given items by means of [specific/nonspecific].... semantic notions" (p.51). And Iwasaki cites two Japanese writers, Oda (1990) and Koizumi (1990), who agree with her that "Japanese students [when speaking Japanese] lack the need to express overtly concepts related to articles such as specificity and definiteness" (p.22). These authors believe that it is the switch from implied definiteness to overt definiteness that constitutes the interference hurdle from Japanese to English. This hurdle also predicted by the Markedness Differential Hypothesis (Eckman 1977). This hypothesis predicts that areas of the target language which differ from the native language and are more marked than the native language will be difficult; whereas, areas of the target language which differ from the native language, but are not more marked than the native language will not be difficult. 1 In the case of articles, the Markedness Differential Hypothesis predicts that, being marked, the articles will be

\footnotetext{
1 Eckman's definition of markedness: "A phenomenon $A$ in some language is more marked than $B$ if the presence of $A$ in a language implies the presence of $B$; but the presence of $B$ does not imply the presence of A." There are languages with both \pm definite and $\varnothing$ articles (French, English), and there are languages that have no articles at all (Chinese and Japanese), but there are no languages that have Idefinite articles without also having $\varnothing$ articles; therefore, the presence of articles implies the presence of $\varnothing$ before nouns, but the presence of $\varnothing$ before nouns does not imply the presence of articles. Therefore, articles would be considered more marked than no articles.
} 
difficult for Japanese speakers to acquire; but that, being unmarked, the article-less NPs and null-NPs of Japanese will not be difficult for English speakers to omit. As to the latter, teachers of Japanese report that their Englishspeaking students deploy article-less NPs and null-NPs with ease (J. Moore 1994, personal communication, August 10, 1994).

Empirical research supports the prediction of the Markedness Differential Hypothesis. Several performance analysis studies (Iwasaki 1990; Thomas, M.1989; Parrish 1987; Yamada and Matsuura 1982; Master 1987) report that Japanese speakers overuse the $\varnothing$ article, transferring the form from Japanese. The same tendency is not found in studies of language groups that do have articles. The overuse of $\varnothing$ (at rates of $47 \%$ in the Iwasaki study and $57 \%$ in the Yamada and Matsuura study) corroborates the widely held view that the Japanese have difficulty expressing definiteness overtly.

Another difference between the two languages is that Japanese, unlike English, does not categorize nouns into tcount and Isingular. All nouns in Japanese are mass (that is, -count), and any noun not marked for number (by a numeral classifier such as three volumes of book, three pages of book) may be construed as either singular or plural (Gil 1987). Since these categorical distinctions are not relevant to the Japanese perception of nouns, yet are 
crucial to the English perception, this difference can slow fluency and discourage acquisition.

One of the most important and overlooked differences between Japanese and English is the cultural component of article usage. Many instances of uniqueness/nonuniqueness are culture-bound. For example, in order to produce the correct article in the sentence on which day of the year does the sun set on the heelstone? a student would need to know that Stonehenge had a unique stone called the "heelstone." Without this vital piece of information, it would be impossible to know whether a heelstone or the heelstone was correct. Similarly, even though an apartment complex may have one hundred units, an American would say thela* roof is leaking because the culture conceives of buildings as having just one roof no matter how large or angled or how many households it shelters. Nothing other than the speaker's cultural heritage informs this use of the. More subtle examples of culture-specific uniqueness are provided by Pica's (1983) research. In higher priced restaurants she found that customers used the more often (I'Il have the tuna melt with chips) because they perceived their orders as unique, i.e., specially placed with the cook and not existing until the order was placed. But in fast food restaurants the use of a was more common (... a Big Mac and a large fries) because customers perceived their orders as typical and probably in a group of similar, 
already-prepared orders. These are cultural-specific cases of uniqueness. Japanese speakers cannot be expected to know the perceptual habits of English-speaking cultures. The important point is that parties to the educational process be aware of the cultural component and attribute usage to that component when appropriate.

This paper will attempt to remedy the problem of article usage for Japanese students only, although the problem is common to all groups whose languages are articleless such as Chinese, Korean, Russian, Czech, and African languages such as Bantu. Several comparative studies have shown (Oller and Redding 1971; Kempf 1975; Ringbom 1976; Dulay and Burt 1974; Fathman 1977;Zobl 1982; Gilbert 1983) that these groups use English articles with greater difficulty than speakers whose languages do have articles (or article-like morphemes) such as French, Spanish, Persian, Arabic and Hebrew.

\section{Complexity of the Article System}

Apart from first-language transfer, another possible reason why the articles are difficult for Japanese speakers to master is that within English grammar as a whole, the article system is unusually complicated. Recognizing this fact, applied linguists often remark that articles seem difficult in spite of their frequency of occurrence in 
native-speaker input ${ }^{2}$. They suggest that structures with high frequency and high difficulty may be more "complex" than other structures (those with low frequency and high difficulty, low frequency and low difficulty, or high frequency and low difficulty).

In 1973, Roger Brown conducted a three-year longitudinal study of the language acquisition of three English-speaking toddlers. He found that all three children, regardless of individual learning environment, acquired particular morphemes of English in the same sequential order. Brown correlated this "natural" order to increasing semantic complexity of the morphemes, and he highlighted the complexity of the article system in particular, providing empirical evidence in support of linguists' intuitions that the article system was an unusually difficult system to master.

At that time, other researchers were looking at the morpheme acquisition of non-native English learners and finding a different "natural" order. They attributed this order not to increasing semantic complexity but to decreasing frequency in the input. More exposures to a morpheme (in ambient speech) equalled speedier acquisition, while fewer exposures equalled slower acquisition. They

\footnotetext{
2 According to Carroll, Davies, and Richman the is by far the most frequent word across all disciplines, $a$ is ranked fourth in frequency and an is ranked thirty-ninth. Adding the adjusted frequencies per million words of these three articles yields a combined frequency of very close to 100,000 per $1,000,000$ words. Put another way, approximatly one word in ten is the, $a$, or an. To the extent that obligatory $\emptyset$ was not counted, we can assume that their estimate is conservative for article usage.
} 
found highest frequency for the articles and also a higher ranking for the articles than Brown had found. However, close examination of the $\mathrm{L} 2^{3}$ methodology shows that the articles ranked as they had in Brown's L1 study, and that therefore, the L2 findings did not contradict Brown's observation that the articles were highly complex.

Brown's data ranked articles as eighth to be acquired out of fourteen morphemes studied. ${ }^{4}$ As to their frequency of occurrence in parental speech, he observed that all three sets of parents used articles more often than other morphemes. 5 Comparing all the frequencies to rank orders, Brown concluded that there was no evidence that parental frequencies influenced the order of acquisition. Greater frequency did not predict speedier acquisition and less frequency did not predict slower acquisition.

The next obvious variable that might explain why children needed more exposures to some morphemes only to acquire them relatively late (or the converse) would be the semantic complexity of the morphemes. After separating the fourteen morphemes into pairs whose members had identical semantic meanings (such as the contractible and

\footnotetext{
${ }^{3} L 2$ means second language; $L 1$ means first language.
}

4 The fourteen morphemes in Brown's survey, in order of acquisition, were:1) Present progressive, 2.5) in 2.5) on 4) Plural 5) Past irregular 6) Possessive 7) Uncontractible copula 8) Articles 9) Past regular 10) Third person regular 11) Third person irregular 12) Uncontractible auxiliary 13) Contractible copula 14) Contractible auxiliary.

5 The parents used articles 552 times. Their next most frequently used morpheme was the thirteenth, 390 times, then 175 times for the seventh morpheme. 
uncontractible copula, I am, I'm) and non-pairs that had unitary meanings (such as the possessive), Brown discovered that, indeed, increasing semantic complexity could explain the general order of the morphemes. Out of all the nonpairs, the articles placed last in order of acquisition. Brown concluded, "It is my impression that [the] specificnonspecific [meaning] is the most complex of these, in some sense or other, and so perhaps the fact that it is the last of the meanings to be acquired is an indication that semantic complexity is a determinant of acquisition order" (p.369).

In the 1970s, morpheme studies were also performed on non-native speakers learning English as a second language. Several of these (Dulay and Burt 1973; Dulay and Burt 1974; Bailey, Madden and Krashen 1974; Larsen-Freeman 1975) discovered sequences that differed from Brown's L1 study yet "correlated statistically" to one another, indicating that semantico-syntactic complexity would not suffice to explain the morpheme orders of L2 learners. To explain these orders, Larsen-Freeman (1976) reintroduced the frequency hypothesis which Brown had rejected.

Larsen-Freeman found that significant correlations existed when she re-examined the speaking task data of her 1975 study and compared it to the frequencies of the obligatory contexts produced by the subjects themselves (on the theory that the counts reflect their actual occurrence 
in real communication). Using Spearman's rank-order correlational analysis, Larsen-Freeman also found significant positive correlations between the frequency input orders from the parents in Brown's study and the morpheme orders in Dulay and Burt 1974 and in Bailey et al., 1974. Tentatively, she concluded that "morpheme frequency in native-speaker speech is the principle determinant for oral production of morpheme order of second language learners" (p.132). Her conclusion contradicted educators' intuitions about articles as well as Brown's findings for the morpheme order of L1 speakers.

However, a close look at just the articles, separated from the other morphemes, revealed that the educators' intuitions and Brown's findings remained valid for the articles, Larsen-Freeman's general conclusion notwithstanding.

To begin with, Larsen-Freeman considered the ten morphemes of her 1975 study as two large groups--a high ranking group (acquired first) and a low-ranking group (acquired last). She then counted the number of obligatory contexts and found them to be generally higher for the top group and generally lower for the bottom group, thus supportive of rank to frequency correspondence. But within the high-ranking group the articles ranked last yet had the highest number of obligatory contexts of any morpheme in the entire study, 825 in all, while the three higher ranking 
morphemes had far fewer obligatory contexts: copula, 224; progressive, 326; auxiliary, 276. Her analysis obscured the special case of the articles, which displayed the familiar pattern of very high frequency and low relative rank demonstrated in the Brown study. In a subsequent survey Larsen-Freeman and Long (1991) commented that the Japanese subgroup in the Larsen-Freeman 1975 study had indicated especially low rank for the articles, supporting the previously described difficulties of language groups which do not express definiteness overtly.

The Bailey et al., 1974 study, which was also used to support the frequency hypothesis, nevertheless ranked the articles fourth in a cross-comparison of just the morphemes studied by all researchers (see Table I). Moreover, when their non-Spanish group, which included Japanese and Chinese speakers, was examined alone, the articles dropped to sixth place. Although Larsen-Freeman did not include the Dulay and Burt 1973 results in her frequency study, their article ranking was also similar to that of Brown and the others. The evidence suggested that the supposed lack of effect for semantic complexity and positive effect for frequency was refuted for the article category. And as expected, the L1 article-less subgroups showed especially low rank for the articles. 
TABLE I

FIRST- AND SECOND-LANGUAGE MORPHEME STUDIES

\begin{tabular}{|c|c|c|c|c|c|c|}
\hline Rank & $\begin{array}{l}\text { Brown } \\
1973 \\
\text { longitudinal; } \\
\text { spontaneous } \\
\text { speech } \\
3 \text { English-speaking } \\
\text { children } \\
\text { ages } 18 \text { mos- } \\
25 \text { mos } \\
\\
14 \text { morphemes }\end{array}$ & $\begin{array}{l}\text { Burt \& Dulay } \\
1973 \\
\text { BSM } \\
151 \text { Spanish- } \\
\text { speaking children } \\
\text { ages 5-8 } \\
8 \text { morphemes }\end{array}$ & $\begin{array}{l}\text { Burt \& Dulay } \\
1974 \\
\text { expanded BSM } \\
\text { Spanish and } \\
\text { Chinese-speaking } \\
\text { children } \\
\text { ages } 6-8\end{array}$ & $\begin{array}{l}\text { Bailey,Madden } \\
\text { Krashen } \\
1974 \\
\text { BSM } \\
73 \text { adults } \\
\text { various languages }\end{array}$ & $\begin{array}{l}\text { Bailey,Madden } \\
\text { Krashen } \\
1974 \\
\text { BSM } \\
\\
73 \text { adults } \\
\text { various languages } \\
\text { (Non-Spanish } \\
\text { group only) } \\
\\
8 \text { morphemes }\end{array}$ & $\begin{array}{l}24 \text { adults in } \\
\text { beginnning ESL; } \\
\text { six each of } \\
\text { Arabic } \\
\text { Japanese } \\
\text { Persian } \\
\text { Spanish } \\
10 \text { morphemes }\end{array}$ \\
\hline$\overline{1}$ & 1.Progressive & 1.Plural & 2.ARTICLES & 1.Progressive & 1.Progressive & 1.Contr Cop \\
\hline 2 & 4.Plural & 2.Progressive & 3.Progressive & 2.Plural & 2.Contr Cop & 2.Progressive \\
\hline 3 & 5.Past Irreg & 3. Contr Cop & 4.Contr Cop & 3.Contr Cop & 3.Past Irreg & 3.Contr Aux \\
\hline 4 & 6.Possessive & 4.Contr Aux & 5.Plural & 4.ARTICLES & 4.Plural & 4.ARTICLES \\
\hline 5 & 8.ARTICLES & 5.ARTICLES & 6.Contr Aux & 5.Past Irreg & 5. Contr Aux & 5.Plural \\
\hline 6 & 10.3rd Pers Reg & 6.Past Irreg & 8.Past Irreg & 6.Possessive & 6.ARTICLES & 6.Possessive \\
\hline 7 & 13.Contr Cop & 7.3rd Pers Reg & 10.Possessive & 7.Contr Aux & 7.3rd Pers Reg & 7.Past Irreg \\
\hline 8 & 14. Contr Aux & 8.Possessive & 11.3rd Pers Reg & 8.3rd Pers Reg & 8.Possessive & 8.3rd Pers Reg \\
\hline
\end{tabular}

This table shows the ranks of the articles when only the morphemes studied by all researchers are compared. The number immediately preceding each morpheme indicates that morpheme's rank in its original study. 
One outstanding exception was the Dulay and Burt 1974 study of Spanish and Chinese-speaking children, which claimed a very high rank for the articles for both language groups. This high rank, especially for the Chinese group, seemed suspicious in light of the many comparative studies which contradicted it, studies which showed that speakers from article-less languages such as Chinese use English articles with greater difficulty than speakers whose languages do have articles such as Spanish (Oller and Redding 1971; Kempf 1975; Ringbom 1976; Dulay and Burt 1974; Fathman 1977;Zobl 1982; Gilbert 1983). For example, in a similar study by Fathman (1975) using sixty korean and sixty Spanish-speaking children aged six to fourteen, the only area that displayed a significant difference between the two groups was the articles. Since the Dulay and Burt 1974 accuracy rate was inconsistent with many other studies on article-less language groups, its results seem unreliable.6 The ESI subjects, who were older than Brown's subjects, but like the Brown subjects, had received more exposures to the articles than to any other forms, achieved a relative proficiency rate for the articles no more easily

\footnotetext{
$6_{\text {It }}$ is hard to guess at the possible methodological causes for the outcome in the Dulay and Burt 1974 study without seeing the raw data. However, the result could be a function of the Bilingual Syntax Measure (BSM), the test which elicits responses to fixed questions about cartoon pictures. Whereas in the Brown study the children's spontaneous interactions with their parents uncovered faulty usages such as the following: Adam:And that the bowl. Mother: What Bowl? (the child incorrectly used the definite article in reference to a bowl unknown to the hearer, his mother), in the BSM, children could overuse the without penalty because the shared knowledge of the cartoon picture would absorb all uses of the yet would also allow a whenever the children saw themselves as informants to the interviewer, introducing new information. The ambiguity allowed by the task may have artificially raised the accuracy rates of a and the. This generosity of the measuring instrument might account for an abnormally high accuracy rate in the Dulay and Burt 1974 study.
} 
than Brown's native learners. This finding seemed to indicate that complexity remained a key consideration in explaining the relative delay/difficulty in acquisition of the article system. And in fact, Larsen-Freeman and Long, after reviewing other studies that also supported a frequency effect, conceded that:

Despite these generally encouraging findings, a few qualifications are in order. First, advocates of a frequency explanation have to account for the fact that articles, which are always by far the most frequent item in (ESL) input, are relatively late acquired, and, like other items in accuracy orders, clearly subject to L1 influence (LarsenFreeman and Long 1991, p. 134).

Even when not considering frequency rates at all, specialists in ESL share Roger Brown's impression that the articles have "...the greatest semantic complexity of the lot" (p.356). They observe that contrasts among the articles are determined by an unusually high number of features (of the noun phrase): count-mass, singular-plural, four possible points of view between the speaker and hearer, and the effects of four possible implicatures. 7 Juggling this amount of complexity on-line would seem to account for the difficulty if not impossibility of using articles proficiently, especially on a conscious level. To the extent that non-native speakers acquire English more consciously than English-speaking children, complexity as defined by the number of grammatical/semantic features,

\section{${ }^{7}$ See page 59}


would seem to belabor L2 acquisition. Exactly what this "complexity" consists of will be the subject of chapter III. The complexity of the article system coupled with teaching materials inadequate to the task, have led students, teachers, and applied linguists to conclude that the English article system is one of most difficult systems to teach/learn. (Larsen-Freeman and Long 1991; Iwasaki 1990; Master 1990; Thompson 1987; Pica 1983; Yamada and Matsuura 1982; Molhot 1980; Lacey 1977; Covitt 1976; Maratsos 1976; Whitman 1974; Grannis 1972).

The Dearth of Adequate Instructional Materials

Surprisingly little material exists for teaching plurals and articles. It is a difficult area, and perhaps a tedious one, but many Japanese feel inhibited in speaking because they have not been trained to make instinctive choices of article and number (Thompson, I. 1987, p. 218).

oddly, despite a consensus that the article system is irksome, little attention has been paid to it by teaching grammars. A survey of forty ESL grammar books published since 1980 (see Appendix A) shows that 28 percent say nothing about articles, while 20 percent stop short of meaning distinctions, limiting their scope to "userfriendly" features such as allomorphic variation between a and an, constructions that favor certain articles (e.g. "use the with geographic locations"), or other clear-choice issues. The remaining 52 percent of the textbooks offer 
vaguely stated rules of thumb with a few examples of dubious worth.

For instance, the latter group frequently advised readers to use a with first mention of a noun and the with second. The advice is succinct, but not sound. Counterexamples abound in everyday language use:

A: Have you heard from Joe?

B: No, but the mail (first mention) hasn't come yet. The trouble (first mention) with Joe is he's moody. A: I'd like to stop at a look-out point (first mention). B: There's one (second mention) up ahead. A: A short hike (first mention) is a good hike (second mention).

Researchers have found that in actual usage the instances of the which do not require prior mention or perceptibility are in "the great majority" (Hawkins 1991, p.415). This observation is supported by Du Bois' data from spoken renditions of the pear film by twenty English speakers. Of the 613 first-mention noun phrases (NPs), 34 percent took the while 4.1 percent of noninitial mentions took a $(n)$. Pica (1983) found in her data on requests for directions from strangers that of the 37 times that a place was introduced with a, only twice was it referred to again with the. The other times the stranger or inquirer used a pronoun (it) or a synonym. 
Paul Christophersen (1939) also found that the firstmention-a; second-mention-the sequence was unnatural. The first two sentences from Stenning's 1976 study illustrate Christophersen's observation: "This chapter describes an experiment. The experiment investigates subjects' comprehension of English articles and quantifiers" (p. 193). Christophersen noted, "There is... a certain aversion to the use of a the-form immediately after the word is introduced; a demonstrative [this, that, these, those] is more usual in such cases: AV Job.1.1 There was a man in the land of $\mathrm{Vz}$, whose name was Iob; and that man was perfect and upright/." (p. 29). The first-and-second-mention phenomena does occur in English but not by virtue of the relation suggested and not often enough to warrant the formation of a rule. Christophersen observed that the greater the distance between a word and its repetition, the more natural it is to use the definite article with the repetition. He used an example from the Grimm brothers: "Once upon a time there was a little princess whose father, the king, was dead, and whose mother, the queen, loved her very tenderly. When the princess grew up...etc." (p. 29) (twenty-two syllables between first mention and second mention of the NP). The controlling principle (as Chapter III will discuss) probably involves mutual knowledge of writer and reader. To introduce a referent into the contextual domain, a writer may use $a$ and thereafter may use the to instruct the reader 
to go back and locate that shared referent in recent memory. Perhaps the "aversion" that Christophersen alluded to results from instructing the reader to locate a referent that is virtually underfoot, its having been just introduced. This would also explain why demonstratives, being more proximate, would seem more appropriate immediately following introductions.

An example of an a-the sequence that is not only awkward but also unacceptable is provided by Grannis (1972): I need a screwdriver to fix this television set. *The screwdriver is the only thing I can get out the tube with (p. 280). In this case and others like it (generic uses), the first-second-mention rule fails altogether. That ESL students could make use of simplifications of these article relations even with the more loosely formulated "previous" and "subsequent mention" rule is contradicted by everyday speech and reading materials. Nevertheless, sixty percent of the textbooks surveyed gave advice similar to that of Lites and Lehman (1990): "The first time you say a noun, use a/an ...After the first time, use the" (p. 58).

A second great failing of the ESL textbooks was the way they described mutual knowledge. Of the twenty-two books that addressed the article system, twelve (54 percent) mentioned speaker-hearer mutual knowledge. 8 Mutual

\footnotetext{
8 None of the textbooks used the term mutual kmowledge, but the wordsknow, knowing, knowledge, or known were used thirty times in phrases having the meaning of mutual knowledge, e.g. "known to both speaker and listener."
} 
knowledge is a complex, pragmatic feature of the definite article whose ramifications cannot be easily reduced to a few pithy statements ${ }^{9}$, yet that was the offering in most cases, e.g.: "Use of the definite article indicates that the speaker... and listener share a definite knowledge about the noun referred to" (Steer and Carlisi 1991, p. 216). One feeble exception was Kirn's Scenario Book 2 (1984a), which gave a list of ways a hearer might "know" what the speaker meant: "1. Sometimes a gesture identifies a noun. 2. Sometimes the identification is in the previous sentence. 3. Sometimes the identification is in the same sentence. 4.Sometimes a noun needs no identification because it is specific from the context..." (p. 85). Other authors described mutual knowledge in a way that only made sense under the interpretation that English speakers can read each others' minds: "The definite article the is used...to show that...both the speaker and the listener are thinking about exactly the same item" (Holschuh 1991, p. 88); "...a noun can be definite because...the people involved in the communication...are living or thinking about the same situation, they know what to expect there." (Feigenbaum 1985, p. 137). Several of the definitions were perplexing because it was hard to tell who the authors were addressing: "Use the article the with a noun when both the speaker and the listener know the specific thing(s) it is referring

\footnotetext{
${ }^{9}$ See pp. $56-58$.
} 
to..." (Robinson 1989, p. 77); "Both the speaker and the listener know which one we are talking about" (Elbaum 1989, p. 194); "We use the when both the speaker and the Iistener know which item is meant" (Davis 1987, p. 19).

Some authors liked to use the example of the earth's moon to illustrate an entity that is universally unique and therefore predictably definite. But having been told to always say the moon, the equator, the sun, etc., what must students think when they hear what English speakers really say? For example, English speakers sometimes say a moon: There's a full moon tonight. Emergency rooms get busy whenever it's a full moon. Students might hypothesize that English-speakers think of the phases of the lunar cycle as non-unique and therefore indefinite. But this cannot be the case: Did you see the full/crescent moon last night? Emergency rooms get busy whenever the moon is full. Even when a lunar phase is not mentioned, speakers still sometimes say a: A moon with a halo means it will rain. There's a moon out tonight. Will there be a moon on Halloween? Perhaps after the word there [existential] speakers say a. On the other hand, one sometimes hears the after the word there [referential]: Hey look, there's the moon--between those two buildings!

Another failing of the textbooks was to equate the numeral one with the definite article. Forty percent of the textbooks made statements such as " ...the limits the 
noun to the one specimen we are familiar with..." (Frank 1972, p. 128), and "...when there is only one person or thing, use the ..." (Lites and Lehman 1990, p. 58). Yet counterexamples are everywhere: The roses are blooming (there is more than one rose); The air is humid (there is not "one air"). Just how definite references are able to isolate more than one object but less than all of the objects in a shared set (e.g. more than one rose, but not all the roses in the garden) has been a topic of contention in the philosophy of English definiteness for at least the last hundred years. The idea that the means one was never one of these philosophies. The terms unique object or unique set is preferred because it implies plurality as well as perceptibility, that is, being perceptibly different from all others. In Christophersen's (1939) historical survey he noted that in all European languages that have an indefinite article, it is of the same root as the numeral one, and in Old English this root was represented by the form an. The definite article, on the other hand, is historically related to the demonstratives this and that. Modern theorists generally agree that when a speaker uses the definite article, he presumes that the hearer will be able to mentally represent the relevant referent within a shared set of objects or mass. If that shared set happens to contain just one object fitting the definite description, then that object is the referent and no modifiers are needed to 
distinguish it from other objects. This is quite different from saying: when there is one object, use the, and implying thereby that if there is more than one, do not use the, to which the roses are blooming is a counterexample; or, neglecting the co-requirement of shared knowledge: $A$ : Hand me the glomper. B: The what? A: There is only one glomper, therefore, you must know what I mean. B: But what is a glomper?

Some of the textbooks claimed that a restrictive relative clause, or other modifier made the referent definite. A few correctly pointed out that this was not always the case. Holschuh (1991b) gave the appropriate warning but, unfortunately, provided a misleading example:

When a noun is identified as a specific object...by a phrase or a clause that follows it...the definite article is used....Be careful! A phrase or clause that follows a noun does not always identify it: I am fascinated by an idea that George mentioned to me. The listener isn't aware of the specific identity of the idea, only that George mentioned it. (p. 262)

But Holschuh's interpretation in this example was misleading because the "specific identity of the idea" had no bearing on the choice of the article. Provided the hearer knew only that a unique idea existed, but not necessarily the content of that idea, the speaker could also have used the. Depending on the context a reader assumed, there were actually three possible interpretations of the indefinite article in Holschuh's example, none of which was the one Holschuh provided: Interpretation 1) The speaker knew that 
the hearer had prior knowledge that George mentioned a unique idea ("X") to the speaker. Under these circumstances, the hearer would have expected the speaker to use the definite article: [As you know] I am fascinated by the idea $[X]$ that George mentioned to me [Let me tell you about it]. But since the speaker instead used the indefinite article, the hearer now had to infer that the speaker was not referring to the idea that he and the speaker were both aware of, idea $\mathrm{X}$, but must have been referring to some other idea that George mentioned: I am fascinated by an idea (not $X$ ) that George mentioned to me. Interpretation 2) The speaker had no prior knowledge of George's mentioning any idea(s) to the speaker. In this case, use of an would mean [You don't know this yet, but] I am fascinated by an idea that George mentioned to me. The hearer would be unable to tell from the speaker's statement whether George had mentioned several ideas, one of which was fascinating, or whether George had mentioned just one fascinating idea. Interpretation 3) The hearer had prior knowledge that George mentioned several ideas to the speaker. In this context, an would mean I am fascinated by an (one of the) idea(s) that George mentioned to me. On Holschuh's interpretation, that George mentioned only one idea to the speaker (as Holschuh seems to suggest by his use of "the idea" and "it" in his explanation), and the hearer knew that George mentioned it, the should have 
been used: [As you know,] I am fascinated by the [one and only] idea (X) that George mentioned to me. [Let me tell you about it]. On the other hand, if the hearer had prior knowledge that George had mentioned several ideas to the speaker, then the speaker correctly chose an, but Holschuh failed to properly account for the speaker's choice by failing to thoroughly disclose the assumed background, namely that George had mentioned several ideas. If students seriously took time to learn rules like Holschuh's, they would have to take additional time to "unlearn" them, picking up counter-evidence by chance in what they read and heard around them. The first rule of second-language instruction, like that of the medical profession, should be "do no harm."

The textbooks shared a common problem in offering too few sample sentences. Most gave two samples per "rule," then a series of fill-in-the-blank exercises. Often, the two examples floated in a context-less void; students apparently were expected to take the author's word when the NP was "(un) known" or "(un) specified." "Tom sat down on a chair. We don't know which chair" (Murphy 1989 p. 134). And, "The most common use of the indefinite article, a(an), is to signal an unspecified item...He wants a bicycle. Notice that there is no attempt to make the noun specific. The noun is indefinite." (Smalley and Hank 1990, p. 105). And from Elbaum (1989), "We use a/an to mean an indefinite 
one. It is not important to know exactly which one: I have a book. I need an eraser" (p. 192).

Too often a "context-less void" surrounded fill-in-theblank exercises. For example, students would be given a battery of unrelated sentences with the articles missing: While he was in park, he saw man walking with dog (Frank 1986b, p.157). Depending on the context envisioned, there could be many correct answers: While he was in the [local] park, he saw the man [he was looking for] walking with a [strange] dog. While he was in a [local] park, he saw a [strange] man walking with the [neighbor's] dog. While he was [visiting] an [unfamiliar] park, he saw $\underline{a}$ man walking with a dog, la boy riding a bike, and a woman strolling a baby.] etc. Despite the variability of interpretation, students were led to believe that there was just one correct answer for each blank.

There were many dizzying instances of circular definition: "When a noun is used in a definite sense, it refers to a specific object..." (Holschuh 1991b, p.261); "Use the definite article, the, when you want to point something out and make it definite...Use the indefinite article, a(an), with singular nouns that are not definite" (Claire 1988, p. 27). Or, "A specific reference is known by the writer and by the reader as something unique, specific, or familiar..." (Raimes 1987, p.131). 
In some places the advice offered by the textbooks was incomprehensible: "Use the with things that are the only ones of their kind. There may be others in the same class of things, but we don't usually think about them" (Claire 1988, p. 24); "The definite article is used before a noun which by reason of locality can represent only one particular thing: Ann is in the garden." (Thomson and Martinet 1986, p.19); "The occurs with names for familiar persons or objects in the home and the community. It is also used with names for natural objects in the world and in the universe" (Frank 1986 a p. 156).

Molhot's (1980) words are as apt today as they were fourteen years ago: "...we need a better definition ...than to say [the] is used for subsequent mention, unique entities, or nouns which have 'undergone' definitization" (p. 14). But to be fair, the faults of ESL textbooks may not lie entirely with their authors. The article system is complicated; adequate treatment requires many different kinds of examples and illustrated contexts. These needs are in opposition to those of textbook publishers who must concern themselves with space and production costs. The limitations of traditional publishing may explain why some authors omitted so much information while others seemed to "load" their rules with too many concepts. 10

\footnotetext{
${ }^{10} \mathrm{An}$ example of a "loaded" rule was found in Chafe (1970): "When we use the definite article the we presume that both we and the hearer know what is being talked about. This is not the case when we use the indefinite article. Most of the words we have considered so far are indefinite; but if we want to express indefinite meaning without any added meaning of amount, etc, we use the indefinite article $a(n)$ (with
} 
For whatever reasons, treatments of the article system have been so poorly handled by some textbooks that the best books turn out to be those which have offered no treatment at all. But despite the shortage of good materials, Japanese students in general do, miraculously, show increasing proficiency over years of study. It is possible that those who improve adopt a strategy to disregard what the grammar books say so that their natural inferences will not be hampered.

Clearly, there is room for improvement, but it is unlikely that the hard copy textbook can ever provide a good solution to the problem. Even the most stellar textbook treatment can only awkwardly capture the heavy contextualization that informs article usage. A computerized tutorial can provide the contextualization, interaction, and attention that the article system deserves.

Throughout most of this chapter the issue of frequency has been raised. Since an article occurs approximately every tenth word, a thirty-percent error rate among Japanese college students manifests as roughly ten errors per page of written text. This high rate suggests that the articles are difficult morphemes to master. The difficulty is corroborated by L1 and L2 morpheme studies, which rank the articles low in order of acquisition/ accuracy. Lack of exposure cannot account for the difficulty since frequency 
of occurrence in native input is optimal. There must be an alternative explanation for the difficulty: semantic complexity is suggested. Given the scope of the problem, one might expect to find thorough treatments of it in teaching grammars, but this is not the case. Authors and publishers have given it scarce attention. The deficiency is revealed by a survey of forty English-as-a-secondlanguage (ESL) textbooks. Considering the complexity of the article system, even improved hard copy textbooks may never be adequate. Computerized tutorials are recommended. Chapter III reviews scholarly investigations of the twentieth century to better understand how native speakers use the article system. 
CHAPTER III

\section{REVIEW OF LITERATURE}

Almost a century of thought underlies modern theories of definiteness. Beginning with Bertrand Russell's 1905 paper "On Denoting" and culminating in John Hawkins' 1991 paper "On (In) definite Articles: Implicatures and (Un) grammaticality Prediction," this scholarly debate has centered around definitions of and interdependencies among certain principles of article usage: uniqueness, shared knowledge, semantic meaning, and pragmatic meaning.

Part I of this chapter surveys investigations prior to the inclusion of H.P. Grice's principles of conversational cooperation. Published in 1975, the ideas in Grice's "Logic and Conversation" began to appear in work on the article system in about 1979. Part II of this chapter shows how Grice's maxims helped explain much of the variability in article interpretation ignored by previous treatments.

\section{EARLY PHILOSOPHIES}

Russel1 1905

Bertrand Russell's 1905 paper, "On Denoting," was one of the first formal accounts of the definite article. 
Russell's theory of meaning fell within an encompassing theory of knowledge and the question of how it is that we know about things we cannot perceive such as points in the solar system or other people's thoughts. We must, he held, rely on words to transmit these ideas. Specifically, we must rely on "denoting phrases," phrases containing words like every, no, some, and the, the last of which he considered "the most interesting and difficult of denoting phrases" (p. 481). To understand the exact meanings of denoting phrases, Russell reduced them to symbols and reduced the sentences in which they functioned to propositions that could then be judged as either true or false. Hence, the father of Charles II was executed reduced to $C(x)$ where $C$ stood for was executed and $x$ stood for the father of Charles II. But whatever statement $C$ might stand for, $C$ (the father of Charles II) implied that Charles II had one father and no more due to the "uniqueness" of the word the: "Now the, when it is strictly used, involves uniqueness...thus when we say ' $x$ was the father of Charles II' we not only assert that $x$ had a certain relation to Charles II, but also that nothing else had this relation" (p.482). Russell reasoned that if the condition that Charles II had only one father failed, then all propositions of the form C(the father of Charles II) would also be false. of course, since charles II had only one father, there could be no such categorical falsehoods. However, statements of 
the kind the present king of France is bald, or $(C$ the present king of France)l, could be false, according to Russell, in three cases: 1) when there is only one king of France and he is not bald; 2) when there is no king of France (nonexistence); 3) when there is more than one king of France (nonuniqueness). If any of these three were true then is bald would be false. Thus, Russell constructed two strict criteria under which, as he put it, the so-and-so, could succeed, namely, existence and uniqueness. Denying either of these would result in the falsity of the proposition. In short, the asserted existence and uniqueness.

Strawson 1950

In 1950, forty-five years after Russell's account, P.F. Strawson challenged the supposed falsehood of the proposition is bald caused by the second of the three conditions, namely, the denial of the existence assertion, i.e., when there is no king of France. Strawson argued that C statements (is bald) were neither true nor false if the presupposed statement (There exists a king of France) were false because there was no king. In other words, the question of the truth of the $\mathrm{C}$ statement (is bald) would be relevant only if the presupposed statement (There exists a king of France) were true; the question of its truth would be irrelevant if the presupposed statement were false in the case where a king of France did not exist. Therefore, 
Strawson reasoned, Russell's analysis did not reflect the correct meaning of the definite article because in ordinary language speakers would not judge sentences like the king of France is bald to be false on the grounds that the existence claim was false; instead, the question of truth or falsity simply would not arise. For all they knew, The king of France could be a fictional king who lived in a golden castle and had a hundred wives. Strawson condemned Russell's use of strict logic and truth conditions for the description of natural language, saying "ordinary language has no logic" (p.344).

Strawson's second point of contention with Russell was over Russell's claim that use of the definite article asserted uniqueness. Rather, strawson argued, use of the definite article made reference to an object that was unique:

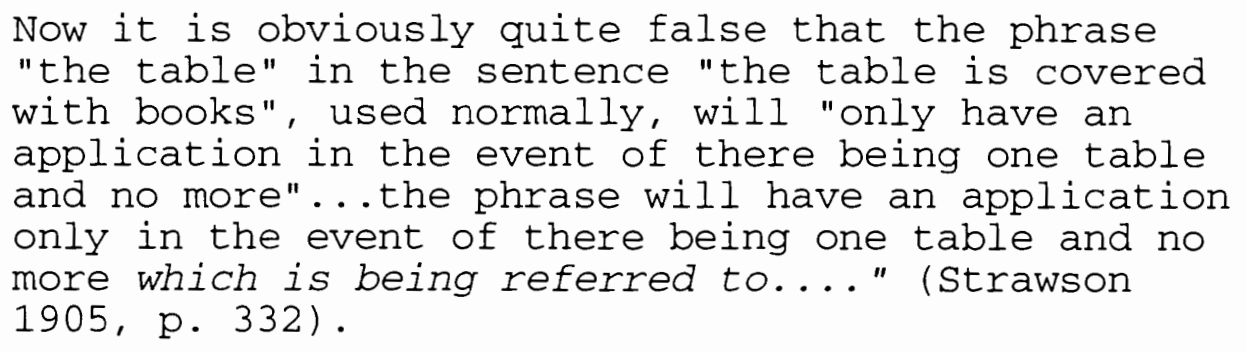
He went on to say that when speakers began a sentence with the so-and-so, the use of the showed that [they] were referring to one particular individual of the species, and they were presuming that the context would "sufficiently determine which one [the speaker had] in mind" ( $p$. 332). It was on the strength of this second argument that strawson 
entitled his paper "On Referring," in distinction to Russell's "On Denoting." The two titles succinctly captured the philosophers' respective positions. Russell's position did not allow a gray area in respect of truth values and did not allow logical form to interact with context. Strawson's position, on the contrary, rejected strict logic altogether and made interaction of form with context a requirement. Both philosopers limited their uniqueness definitions to singular nouns, making no provisions for plural or mass nouns.

McCawley (1981) pointed out that Strawson's modification of uniqueness did not go so far as to allow that speakers could successfully refer to one prominent object out of several similar ones, the prominence of the one being decided by context. McCawley's example, The restaurant on Clark street is excellent, illustrated how, when uttered by the right speaker to the right hearer at the right place and time could identify a particular restaurant out of many. In other words, strawson had overlooked Russell's third case of alleged falsehood--when there is more than one king.

Jespersen 1933

Otto Jespersen devoted twenty pages to the definite and indefinite articles in his Essentials of English Grammar (1933). Mostly it was a listing of occasional uses such as 
the with names of oceans, titles of persons, countries, streets, etc. But in one phrase he spoke of the use of the definite article to indicate the thing that "is uppermost in the mind of the speaker and presumably in that of the hearer too" (p. 162). This insight was a glimmer of the speakerhearer knowledge issue that future linguists would examine very closely.

\section{Christophersen 1939}

The idea of speaker-hearer knowledge was expanded into the theory of familiarity by Paul Christophersen in his 1939 treatise, The Articles.11 Unlike Jespersen's view, which saw hearer knowledge as peripheral to definite reference, Christophersen's theory saw hearer knowledge as central: "A condition of the use of the is that there is a basis of understanding between speaker and hearer... and the speaker as the active party must... adapt his language to the hearer's state of mind" (p. 28). Probing the notion of hearer knowledge more deeply, Christophersen identified three "bases of understanding" which a speaker could use to reasonably predict that a hearer would comprehend a definite reference: 1) explicit contextual basis (introduction and subsequent mention, i.e., Once upon a time there lived an old tailor in a small village. The tailor...etc.); 2) implicit contextual basis (having mentioned to swear a speaker could

\footnotetext{
${ }^{11}$ Christophersen wrote, "The familiarity-theory is widespread and old." He referred to Aa Hansen's dissertation Bestemt og ubestemt Substantiv. Copenhagen 1927 and to G. Brown's The Grammar of English Grammars. New York 1861.
} 
then go on to talk about the oath or having spoken the words a tailor could then say the man); and 3) situational basis (situated in a railway-carriage, the speaker could begin a conversation about the [Iuggage] rack). Provided that a basis existed, a speaker could use the to signal a hearer that a referent was in some way "familiar" to both of them. Unlike Russell, Christophersen argued that the definite article could refer to one prominent object out of several similar ones (i.e. when there is more than one king). He wrote, "The existence of the proper basis of understanding means that the hearer's field of attention is so narrow at the moment of receiving the communication that only one individual (the one meant) is evoked mentally by the theform" (p. 29). As with singular entities, the could mark off precise limits when referring to plurals as in keep clear of the Propellers (notice on steamers in harbour) ( $\mathrm{p}$. 36), and could isolate parts out of wholes when referring to mass nouns such as water: She poured some water in a kettle and put it on the fire; half a minute later the water was boiling (p. 34 ).

Christophersen's familiarity theory emphasized the basis of understanding between interlocutors. "...the article the is to refer to this basis, to indicate 'the thing you know" (p. 70).

Searle 1969 
John Searle sought to define the definite article within speech act theory. He argued that in the act of definitely referring a speaker picked out, or identified a particular object which he could then go on to talk about. Upon being asked "what?" or "who?" in reply to a definite reference ( $A$ :The man...B: What man?), the speaker could "guarantee" a description that would positively identify the referent for the hearer. The use of the implied the guarantee. Searle outlined three ways that the guarantee could be communicated, either implicitly by the article the, or explicitly, on demand: 1) the utterance could contain a description true only of the object; 2) the utterance in combination with the context could provide an ostensive or indexical presentation of the object; 3) the utterance could contain some combination of these two. But Searle was mainly concerned that referring be the act of picking out an object that happened to exist and be unique. Instead of hitting an individual on the head to pick him out, speakers could refer to him. Thus, speakers could "do things with words. " 12

Hawkins 1978

In Definiteness and Indefiniteness (1978) John Hawkins claimed that use of the definite article was an instruction to the hearer to "locate" a referent among a shared set of

\footnotetext{
12 from J. L. Austin (1955) How to Do Things with Words.
} 
objects. Like Christophersen, Hawkins described how speakers, by using the, could not only isolate a single object among several similar ones, but could also mark off precise limits of plurals, and could identify subparts of mass entities. This precision Hawkins called inclusiveness. Once the hearer located the set of shared objects, use of the referred "inclusively" to all the objects within a domain of quantification which [had already been] pragmatically restricted" (p. 160). The sentence bring in the wickets referred inclusively to all six wickets on a particular cricket field, not to four or five wickets. Reference to a set meant reference to all the pragmatically relevant objects in the set. Thus, the with singular nouns was an instance of inclusive reference to ALL, which happened to equal a totality of just one object. Following searle, speakers in Hawkins' location theory performed not one but three speech acts whenever they used the definite article: 1) they introduced a referent (s) (wickets) 2) they instructed the hearer to locate the referent(s) in a shared set of objects (the wickets on a particular playing field), and 3 ) they referred to all the objects or mass within this set that satisfied the pragmatics of the sentence (all six wickets).

The indefinite article (a/some) referred exclusively to only a subset of the relevent objects, as in bring in some wickets. But when the NP had a potential uniqueness 
relationship with the shared set, the indefinite article could not refer to that object, and the hearer had to search outside the shared set in order to locate the correct referent. In Hawkins' example, I bought a book and talked to an author about it, the NP, author, had a potential uniqueness relationship with the shared set, the book. Therefore the would be the expected choice of article. However, since the speaker chose an author, the correct referent could not be the author holding the uniqueness relationship with the shared set, the author of the book in question; consequently, the hearer had to search outside the relevant set to find the correct referent, the author of some other book. Unlike the definite article which to referred to ALL the relevant members of a set, the indefinite article either referred exclusively outside the shared set (to the author of some other book) or, when there was no potential uniqueness relationship, it referred exclusively to a subset of the shared set (some of the wickets).

\section{Summary}

Except in the case of Russell, all of the foregoing discussions bore on issues of reference and speaker-hearer knowledge. Russell argued that the asserted uniqueness and existence; Strawson replied that it referred to a uniquely existing object. Jespersen hinted at speaker-hearer knowledge; Christophersen elaborated on common bases of understanding, or "familiarity" conditions by which a 
speaker could know a hearer's mind. Searle maintained that speakers used the definite article to communicate uniquely existential propositions (facts). He defined referring as the act of picking out an object, then saying something about it. For Hawkins, the definite article instructed the hearer to locate the referent in a shared set of objects. The sentence referred to all the objects in that set, which had already been pragmatically delimited. The aim of the next section is to show how Gricean principles of conversation caused Hawkins to revise his theory.

\section{LATER PHILOSOPHIES}

\section{Grice 1975}

In an influential paper in 1975, H.P.Grice put forth his view of language use as a manifestation of human cooperation. One feature of this view was that speakers were able to convey (and intended to convey) more information than they actually uttered. This was because hearers naturally expected speakers to make statements that showed a spirit of cooperative talk exchange, statements that were true, informative, clear, and relevant; and, when speakers seemed to fall short of these four maxims, hearers managed rich interpretations that fullfilled their expectations just the same (Newmeyer 1986). Put crudely, hearers filled in the gaps. An example was given by Kempson (1988): A: What's the new Pizza House like? B: The cooks are 
Italian. B's response implied that the food was authentic and delicious yet inexpensive, that the coffee was good, etc. This response conveyed more information than a direct answer would have and was thus more relevant. Grice coined the term implicature to mean the information conveyed by an utterance over and above its propositional content. In Kempson's example, the propositional content was that the cooks were Italian. The implicatures were that the food was delicious yet inexpensive, the atmosphere was relaxed, or whatever else the hearer employed to satisfy the Maxim of Relevance, the maxim that seemed to have been violated by the indirectness of B's response but in fact was not. Relevant information was implicated by $B$, inferred by $A$. As Sperber \& Wilson (1986) noted "Grice put forward an idea of fundamental importance: that the very act of communicating creates expectations which it then exploits" (p. 37) .

Not only could the meanings of whole utterances be better understood in terms of implicatures, but individual words could, too. For example, it was observed that logical connectives such as and, or, if...then, not made richer contributions to natural language utterances than could be represented by their logical denotations. These richer meanings could be explained in terms of implicatures. For instance, the conventional lexical entry for the word and was its function as a logical conjunction. But in the 
sentence put the gear shift into neutral and turn the key in the ignition, the word and would be enriched to and then by the Maxim of Manner, "be orderly," or "be sequential."

After the publication of Grice's paper, linguists continued to develop implicature theories of increasing subtlty to explain regularities of language use that semantic and syntactic theories had failed to capture. The contrast between the and a would be one such regularity.

Critiques of Hawkins' 1978 theory led him to write an article which he published in 1991, wherein he revised his theory and incorporated many of his critics' ideas. In this revised article, entitled "On (In)definite Articles: Implicatures and (Un)grammatically Prediction" (1991), Hawkins drew on the works of many authors (Sperber \& Wilson, Levinson, Kempson, and Horn) to create a "neo-Gricean" implicature theory of article usage.

\section{Reviews of Hawkins 1978}

Many of Hawkins' critics found that some of the functions he attributed to conventional meanings of the articles were actually the result of Gricean implicature.

For example, Hawkins had claimed that definite reference to a set meant reference to all of the objects in the set satisfying the descriptive predicate or context. Declerk (1987) disputed such a comprehensive definition of the definite article. He argued that the meaning of the could be split in two. In its conventional meaning, the 
meant reference just to a (shared) set, whereas in its conversational meaning, the meant reference to all the objects in the set unless pragmatic factors excluded some of the objects. Declerck contended that the former meaning, which in essence was Hawkins' instruction to "locate" a shared set, was inherent to the definite article, whereas the latter meaning followed as an implicature from its use. The origin of this implicature was Grice's Maxim of Quantity, which said that the speaker must make his contribution as informative as required for the purposes of the comunicative exchange. If the speaker wanted to limit the set to a subset, he had to do so explicitely (bring in three of the wickets), but if the speaker did not explicitely limit the shared set, the hearer had the right, by the Maxim of Quantity, to assume that the speaker had been as informative as necessary and that, therefore, reference was to the whole shared set, e.g., to "all the wickets." Thus, for Declerck, "inclusiveness" within the shared set, (i.e., delimitation to a subset), was a pragmatic function of the rest of sentence (or context) in conjunction with the definite article, but was not, as Hawkins had claimed, an inherent function of the definite article itself.

Ewan Klein saw implicature theory as an alternative to Hawkins' analysis of the indefinite article. He observed that the was logically stronger than $a$ and that by Grice's 
Maxim of Quantity a speaker should use the if he were in a position to do so. Therefore, if he used a, he was conversationally implicating that he could not make the "inclusiveness" claim associated with the.

D.A. Cruse also suggested conversational implicature in the use of a: "First, we need to assume a general conversational principle that a speaker MUST use a definite article if he can do so appropriately" (p. 314).

John Hawkins 1991

In 1991, John Hawkins revised his location theory to include, among other changes, conversational implicatures. But first, he redefined several terms. He resurrected and updated Bertrand Russell's 1905 claim that use of the asserted existence and uniqueness. He updated it by saying that the claim only held within certain pragmatic parameters, or P-sets, as he called them. The P-sets were similar to Hawkins 1978 "uses" and to Christophersen's "bases of understanding." They were: 1) physical setting [of the utterance] set; 2) "Iinguistic" community set; 3) set resulting from briaging ${ }^{13}$; and, 4) previous discourse set. Existence and uniqueness were asserted by the, but were only definable relative to a $\mathrm{P}$-set.

${ }^{13}$ The term bridging was first used by Clark and Haviland (1977) to describe certain inferences that the speaker intends the hearer to draw in order to compute the intended antecedent. The hearer bridges, or constructs certain implicatures to compute the antecedent. Consider, l looked into the room. The ceiling was high. Since all rooms have one ceiling, the ceiling can be definite provided the hearer constructs the following bridge, or implicature: The room mentioned has a ceiling; that ceiling is the antecedent of the ceiling. 
A second change in Hawkins' revised theory was to expand the definition of uniqueness. Since the term unique connoted one, it worked well when Russell had applied it to singular nouns such as the father of Charles II. But when applied to plurals and mass nouns, unique was a contradiction in terms. To avoid this problem in his original theory, Hawkins had used the term "inclusiveness", i.e.the referred "inclusively" to ALL the relevant object(s) or mass in a shared set. In the 1991 revision, Hawkins went back to Russell's term, unique, but broadened it so that all uses of the term unique were to be understood as unique maximal set, a suggestion made by Klein (1980). In this way, plurals such as the bridesmaids would comprise a unique maximal set of bridesmaids and the cake would comprise a unique maximal amount of cake in a P-set such as a wedding.

A third change in Hawkins' 1991 theory was to abandon the term shared knowledge 14 in favor of Sperber \& Wilson's (1986), mutual manifestness and mutual cognitive environments. The term shared knowledge had implied an epistemological knowledge that was shared a priori. The term had failed to accomodate first-mention uses of the, uses where the hearer had no knowledge of the referent before its initial mention. These, according to Hawkins,

14 The term mutual knowledge is found throughout the literature on definiteness ( $x x x)$, but as Sperber \& Wilson (1986) argue, the term has problems of infinite regress, e.g., She knows that he knows that she knows that she doesn't see what he sees, etc., ad infinitum. In other words, knowledge can only be mutual after an infinite number of regressions, hence mutual knowledge is an insolvable paradox. 
were the vast majority of instances in English. Hawkins' new terms, mutual manifestness and mutual cognitive environments, broadened the kind of knowledge that definite reference would allow by making it cognitive rather than epistemological. If a fact or an assumption were manifest to an individual, he was capable of representing it mentally and accepting it as true or probably true. An indivdual's cognitive environment consisted of all the facts and assumptions that could be perceived or inferred because they were manifest. The expression mutual cognitive environment referred to all of the facts and assumptions manifest to speaker and hearer: "Peter and Mary are talking to each other in the same room: they share a cognitive environment which consists of all the facts made manifest to them by their presence in this room. One of these facts is that fact that they share this environment" (p. 41).

With the concept manifest knowledge it was now possible to explain how a speaker could use the even though a hearer had no prior knowledge, in the epistemological sense, of the referent. As Christophersen (1939) had observed, these were cases when "the [author] preferred to jump in medias res and leave the reader to find out for himself what [was] meant...Example: Wells (The Invisible Man) The stranger came in February" (p. 29). A reader could "mentally represent," or imagine, a unique and existing stranger on the author's word, without previous mention of 
one.15 Mutually manifest knowledge could account for all the counterexamples to the prior-mention-takes-a-subsequentmention-takes-the notion because a speaker could say the whenever he judged a noun to be mutually manifest to himself and his hearer.

The most important change in Hawkins' theory was to explain (in)definite reference in terms of Gricean implicatures. Instead of referring directly to an entity, the article+NP+context framework conversationally implicated pragmatic parameters (P-sets) and uniqueness values relative to which an entity could be located and identified as the entity meant. In the case of the definite article there was also a conventional implicature, which functioned independently of conversational analysis. A conventional implicature was "essential to the meaning of [a word], rather than derived from that meaning by means of conversational principles" (Leech 1983, p. 90). In Hawkins' revised system the conventionally implicated that there was some set of entities, $\{\mathrm{P}\}$, in the universe of discourse which was mutually manifest to speaker and hearer on-line and within which definite referent(s) existed and were unique.

15 Brown (1973) also observed the use of the definite article in medias res. "It seems as if the speaker when he knows more about a given stable part-whole relation than his listener sometimes speaks from his own information letting his choice of article instruct the listener" The part-whole relation he referred to was in the example The tenor soloist in Verdi's Requiem. A hearer might not have prior knowledge of Verdi's Requiem having only one tenor soloist; nevertheless, a speaker might choose the as a kind of instruction to the listener. (p. 347). 
In addition to inducing a conventional implicature, the could also induce one conversational implicature--by the (I)-Principle. Inducing no conventional implicatures, a/some could induce only conversational implicatures--by the (Q)-Principle and the (I)-Principle. Both the (Q)- and the (I) - Principles were adapted from Levinson's (1983, 1987) refinements of Gricean Maxims. The (Q)-Principle required the speaker to not provide a statement that was informationally weaker than his knowledge of the world allowed. The hearer's corollary to the (Q)-Principle required the hearer to take the speaker's statement as the strongest statement the speaker could make consistent with what the speaker knew. If the speaker said some of my best friends are academics, the hearer should take it that not all of my best friends are academics because the stronger statement, all of my best friends are academics was not used, and therefore its negation was implicated.

The (I) Principle required the speaker to say as little as possible (produce the minimal linguistic structures) to achieve his communicational end. The hearer's corollary required the hearer to enrich the content of the speaker's utterance by finding the most specific likely interpretation. If the speaker said if you mow the lawn I'Il give you \$20, the hearer should infer if you mow the lawn, and only if you mow the lawn, I'Il give you $\$ 20$. 
There was an obvious tension between these two principles: the speaker should make the informationally strongest statement by the (Q)-Principle, yet should also make the minimal linguistic statement by the (I)-Principle. But the two could function at once, according to Levinson, because Q-implicatures were calculated first and were limited to a small set of Iinguistic expressions on Horn scales such as $\langle\mathrm{n}, \ldots 5,4,3,2,1\rangle$; <all, most, many, some, few>; <excellent, goods. The selection of a weaker item on the right of a scale would induce implicatures negating all items to the left. Thus, the meal was good would (Q)implicate that the meal was not excellent. If the $(Q)-$ Principle applied, then the (I)-Principle did not apply. If the (Q)-Principle did not apply then the (I)-Principle could.

Hawkins argued that the articles were also arranged on a Horn scale, <the, a>. The selection of a implied the negation of the, provided the could have been used. If the could not have been used, then the (Q)-Principle would not apply. For example, in an American newspaper headline such as a president has resigned, the stronger form, the, could have been used because there is a unique American president. But because the writer chose the informationally weaker form, $a$, he effectively negated the and thereby induced the (Q)-implicature not the president lof the country] has resigned [but the president of some other 
country]. On the other hand, in the headline a senator has resigned, the could not have been used because the uniqueness requirement did not obtain (i.e., senator is not unique). Therefore, the (Q)-Principle did not apply (and its implicature, not the, did not apply). Instead, if a Pset existed in which the referent could exist (in this case a set did exist in the set of U.S. senators), then the (I)Principle induced the richer statement one of the senators has resigned. To select the correct implicature for the indefinite article, the hearer had to first determine whether or not the could have been used. If it could have been used (because the referent was a unique maximal set and because there was mutual manifest knowledge), then the (Q)Principle applied and a meant not the. Conversely, if the could not have been used (because either uniqueness or mutual manifest knowledge or both did not obtain), then the (Q)-Principle did not apply; instead, provided a P-set existed, a was enriched by the (I)-Principle to one of the. Enrichment to one of the was only implicated if pragmatic information allowed (i.e., if a $\mathrm{P}$-set existed in the conversational context). If pragmatic conditions did not allow enrichment, then a would simply remain a and the NP would be interpreted as non-unique and not a $P$-set member. 16

16 The statement / am fascinated by an idea that George mentioned to me can be interpreted three ways in terms of implicature theory: Interpretation 1) if the could have been used (because the requirements for its conventional implicature obtained, that is, the hearer knew there was a unique idea and that George mentioned it), then use of an would (Q)-implicate non-uniqueness, i.e., not the idea in the $P$-set but some other idea outside the P-set; Interpretation 2) if there were a P-set in which the referent 
While the indefinite article induced either a (Q)-or (I)-implicature, the definite article induced either the conventional implicature or, in cases of bridging, an (I)implicature. The (I)-implicated that if a P-set existed in which it were possible for the NP to be unique, then the NP was indeed unique within that $\mathrm{p}$-set. For example, mention of the class allowed mention of the professor because there was a P-set, the class, in which the professor could be unique. The (I)-Principle enriched the professor to the professor of the class. All cases where the (I)-implicated were cases of bridging.

To summarize, the implicature induced by a/some of nonuniqueness ("not the") resulted in non-P-membership of unique entities (not the president) by the (Q)-Principle (do not say more than you know). The implicature induced by a/some of P-membership ("one of the") for non-unique entities (a senator) was made possible by the (I)-Principle (do not be prolix). The (I)-implicature (induced by the) of P-membership ("of the") for unique entities (the professor) was possible if there was a P-set (the class). Finally, the conventional implicature (induced by the) meant that there was a mutually manifest P-set within which the NP existed and was unique; the hearer should locate it.

could exist (i.e.,the hearer knew that George had mentioned several ideas to the speaker), then use of an would (1)-implicate P-membership. That is, this idea was one of the ones George mentioned, and an would be enriched to one of the ideas; Interpretation 3) if there were no P-set (i.e., the hearer had no knowledge of George's mentioning any ideas to the speaker), then use of an would implicate non-P-membership, and the hearer would not be able to infer if an were unique (an idea) or not unique (one of the ideas). 
John Hawkin's implicature theory will serve as the theoretical background for the design of the tutorial, illustrated in Chapters IV and V. 
CHAPTER IV

THE VISUALS FOR THE TUTORIAL

The illustrations on the following pages should be considered visual aids to understanding the sampling of story scripts in Chapter IV. Each illustration represents a frame excerpted from the story "Eric Opens a Window." The illustrations show what a user would see on the screen: the command options in the margins and the visual gimmick for the characters' "asides"--the small screen with a small Kato and Eric surrrounded by the "real" screen with a large Kato and Eric.

In an actual tutorial, a brief introduction to the pragmatics of article function would precede the stories so that terms in the explanations such as unique and manifest would have clear meanings to the user.

The grammatical explanations are complex and well beyond the level of the average high school student, even in translation. The intended audience is college and graduatelevel students. Teachers of ESL, both English-speaking and Japanese-speaking, could also find the explanations insightful. 


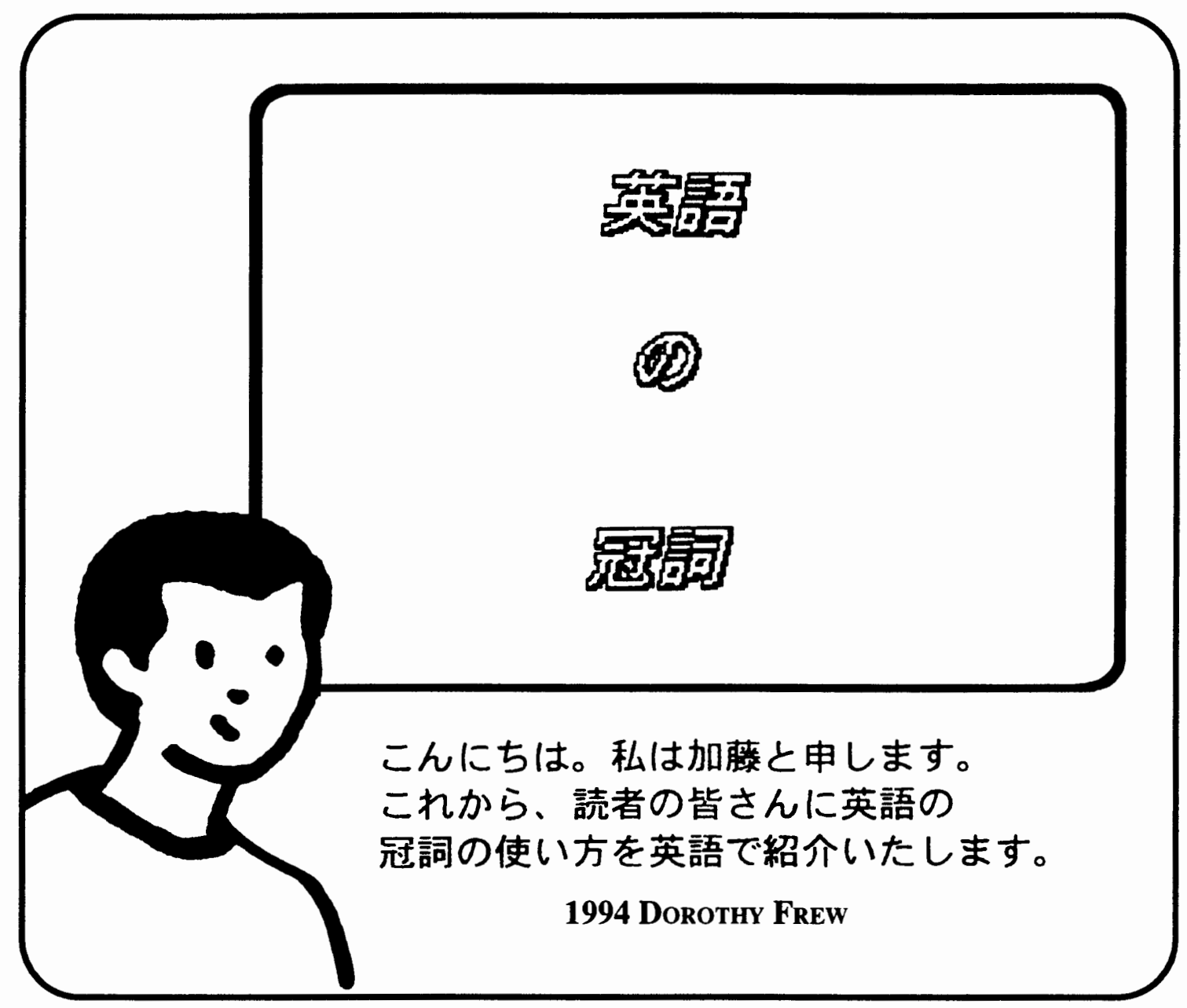




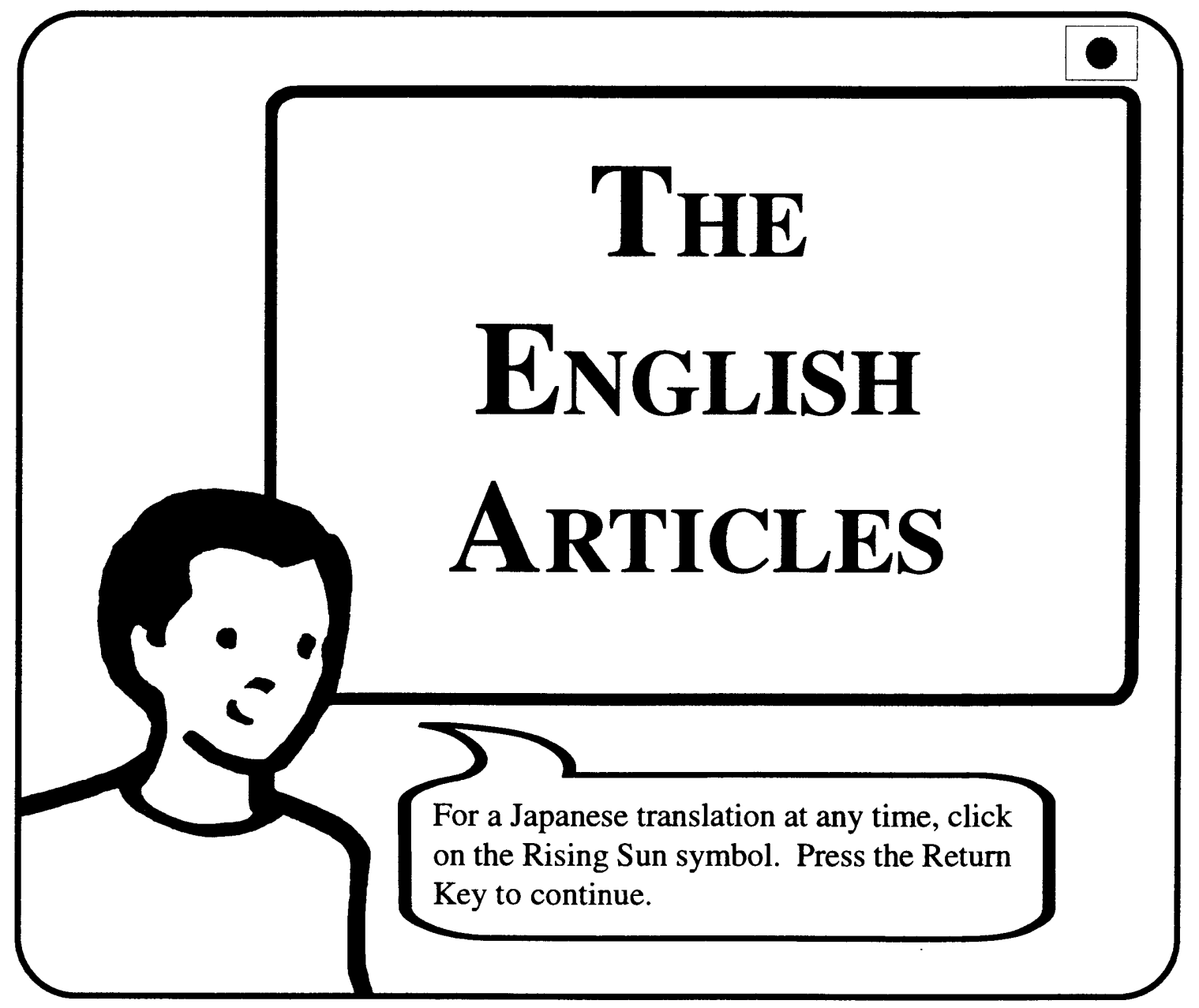




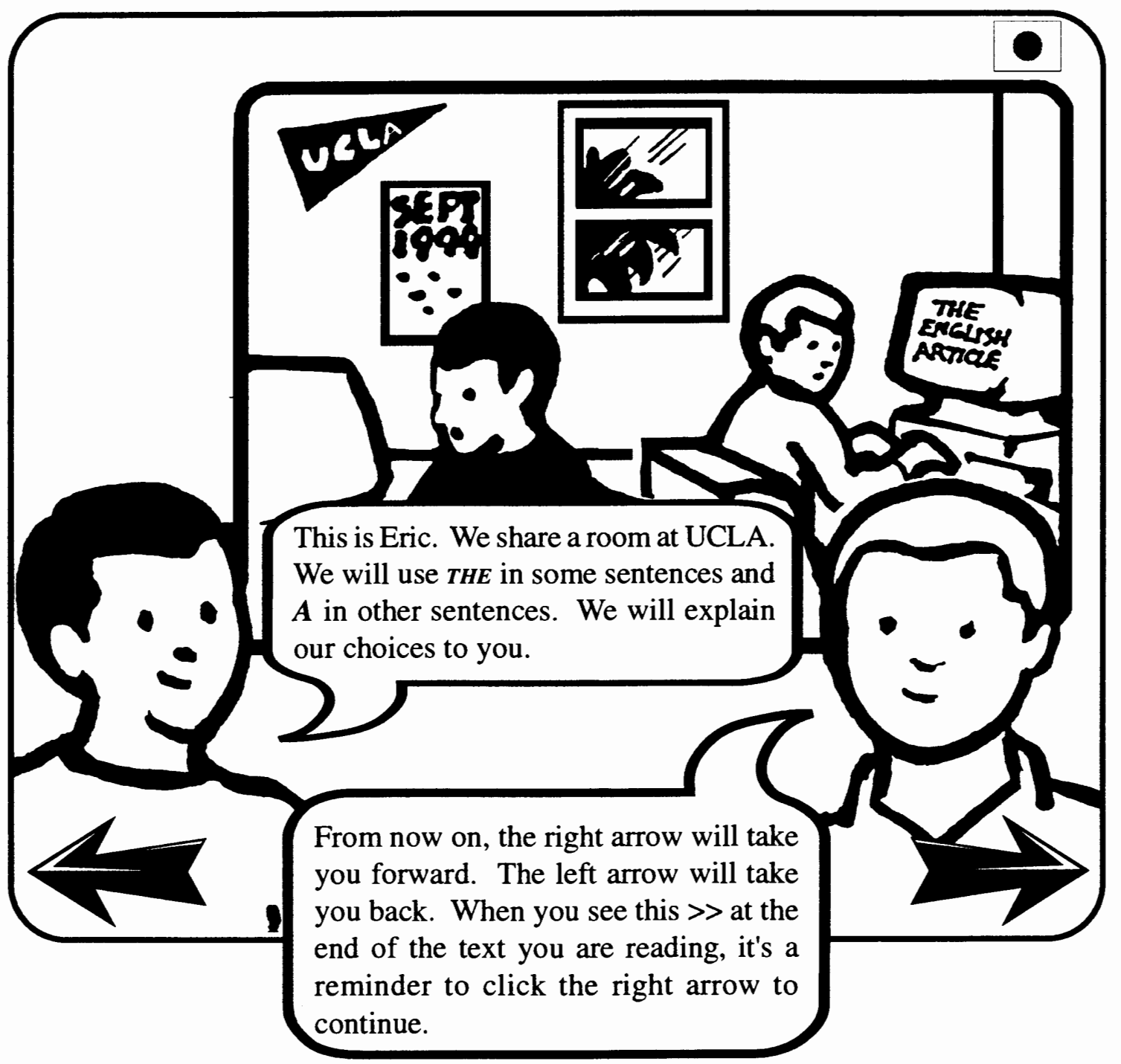




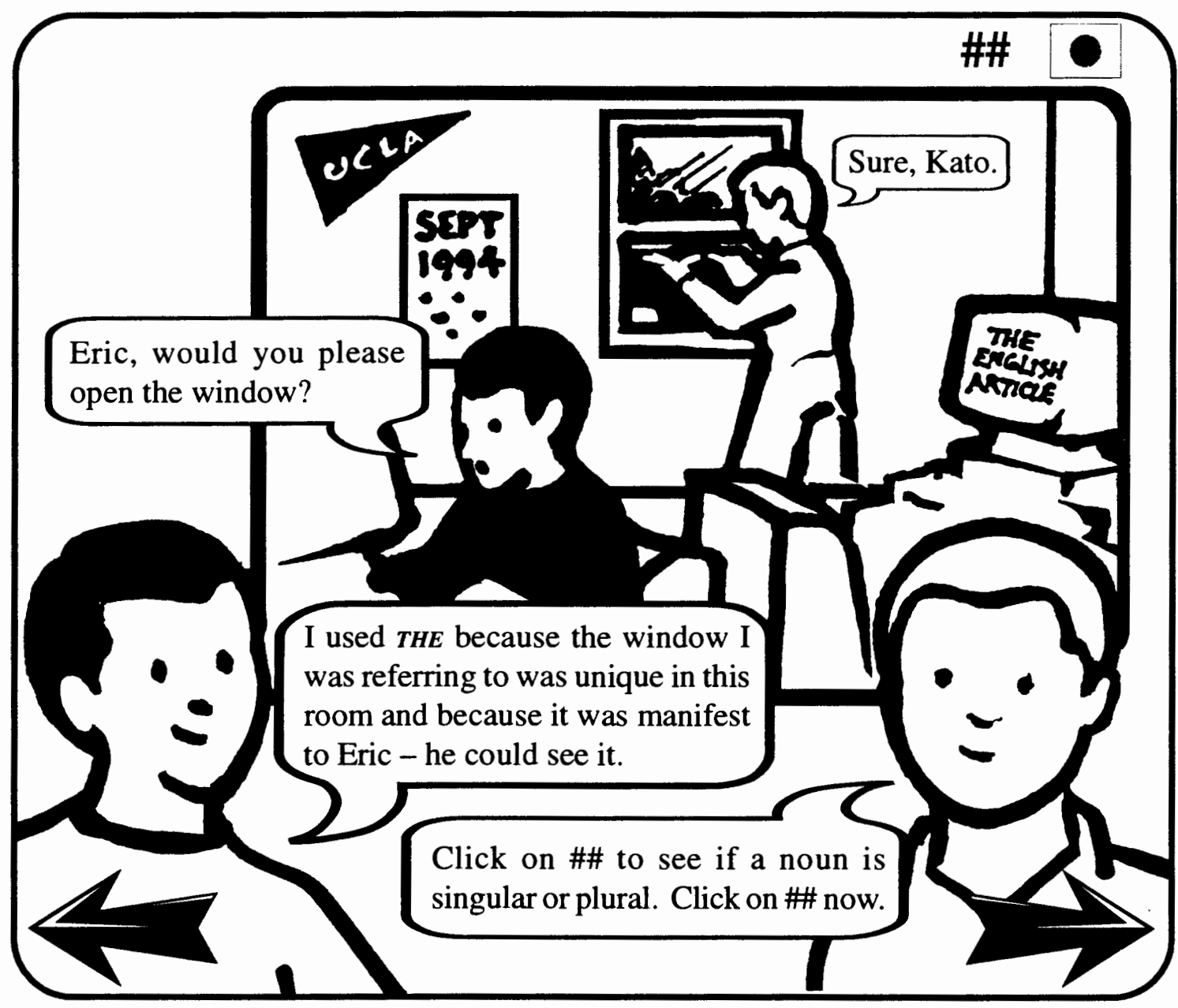




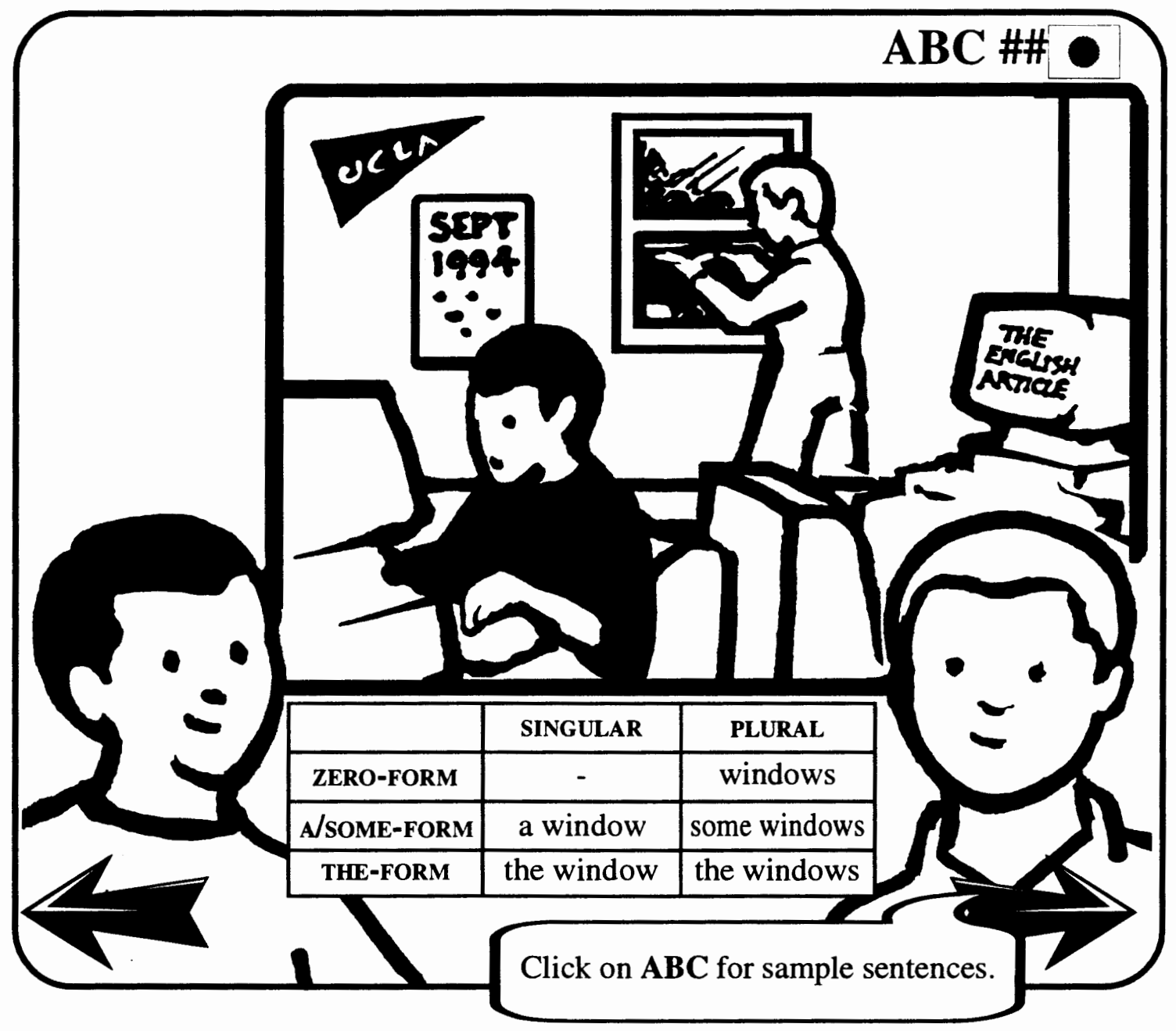




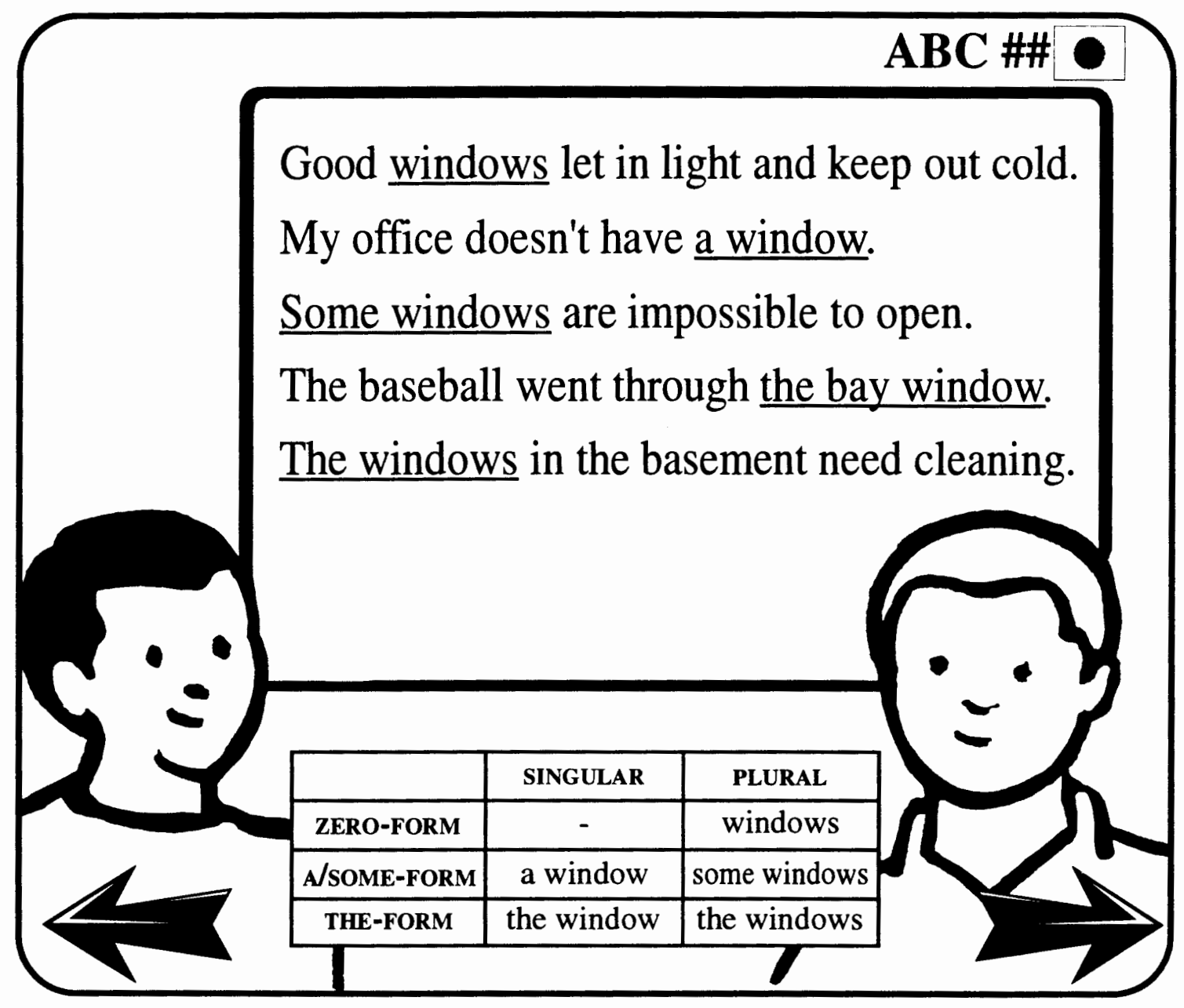




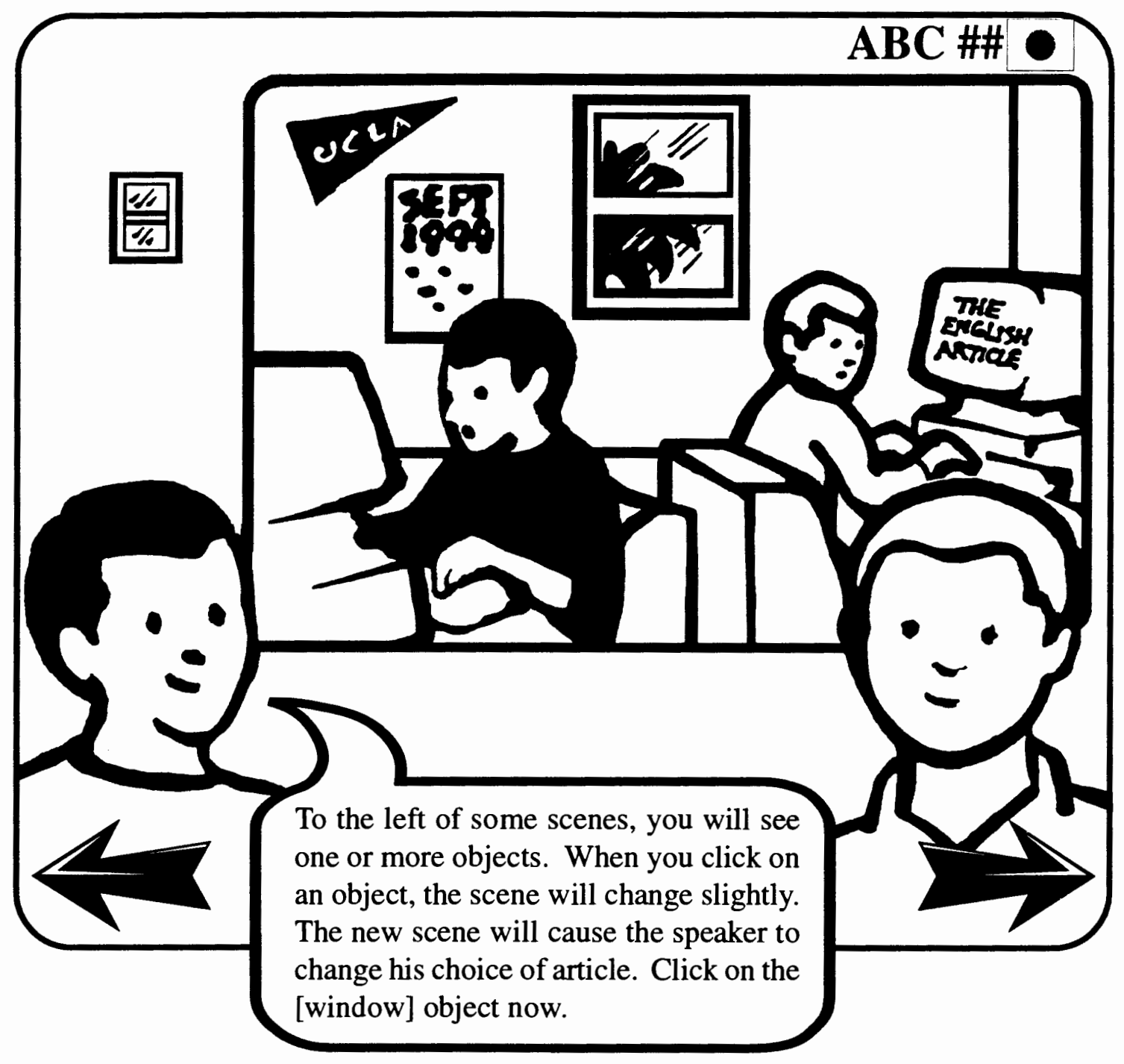




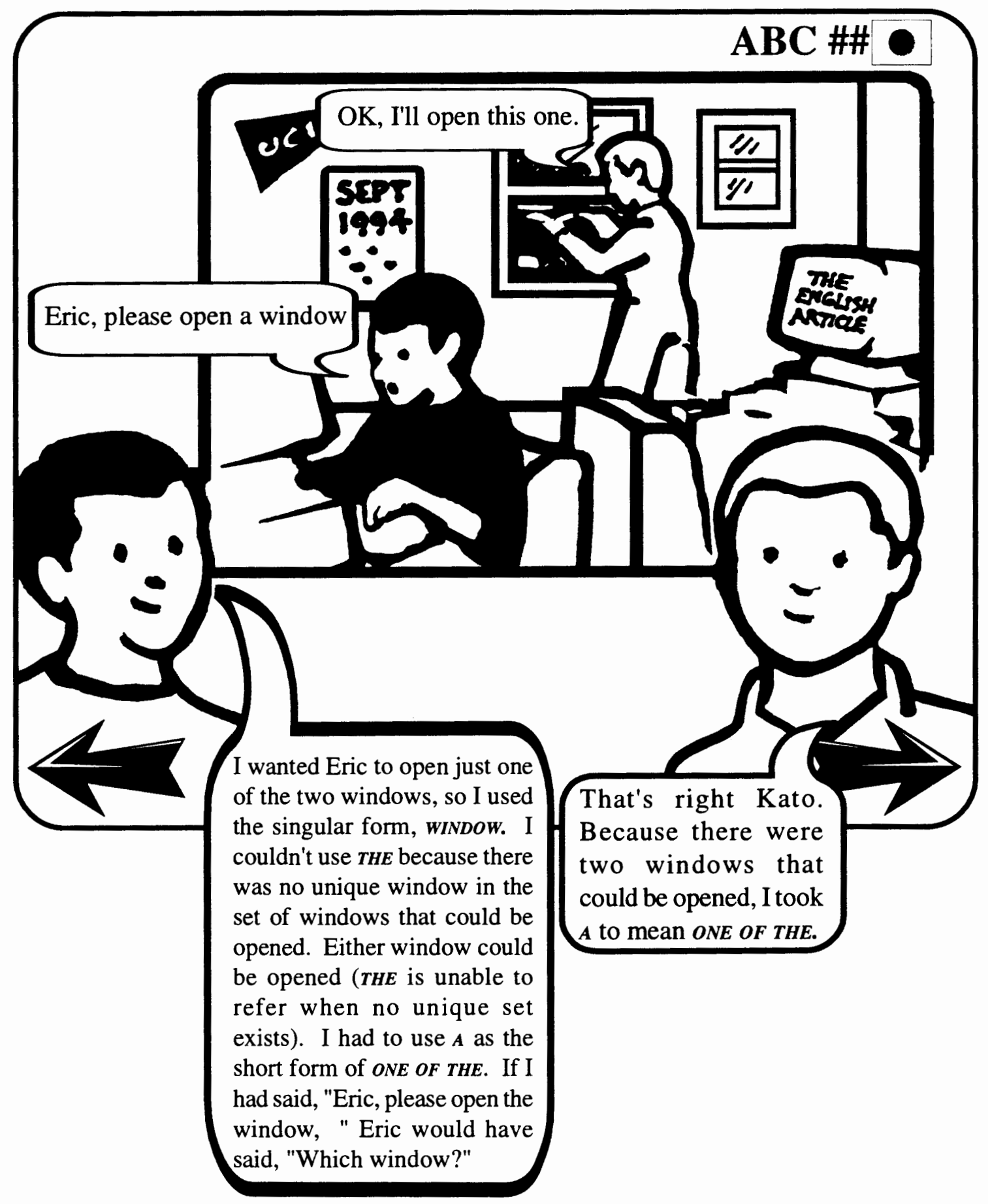




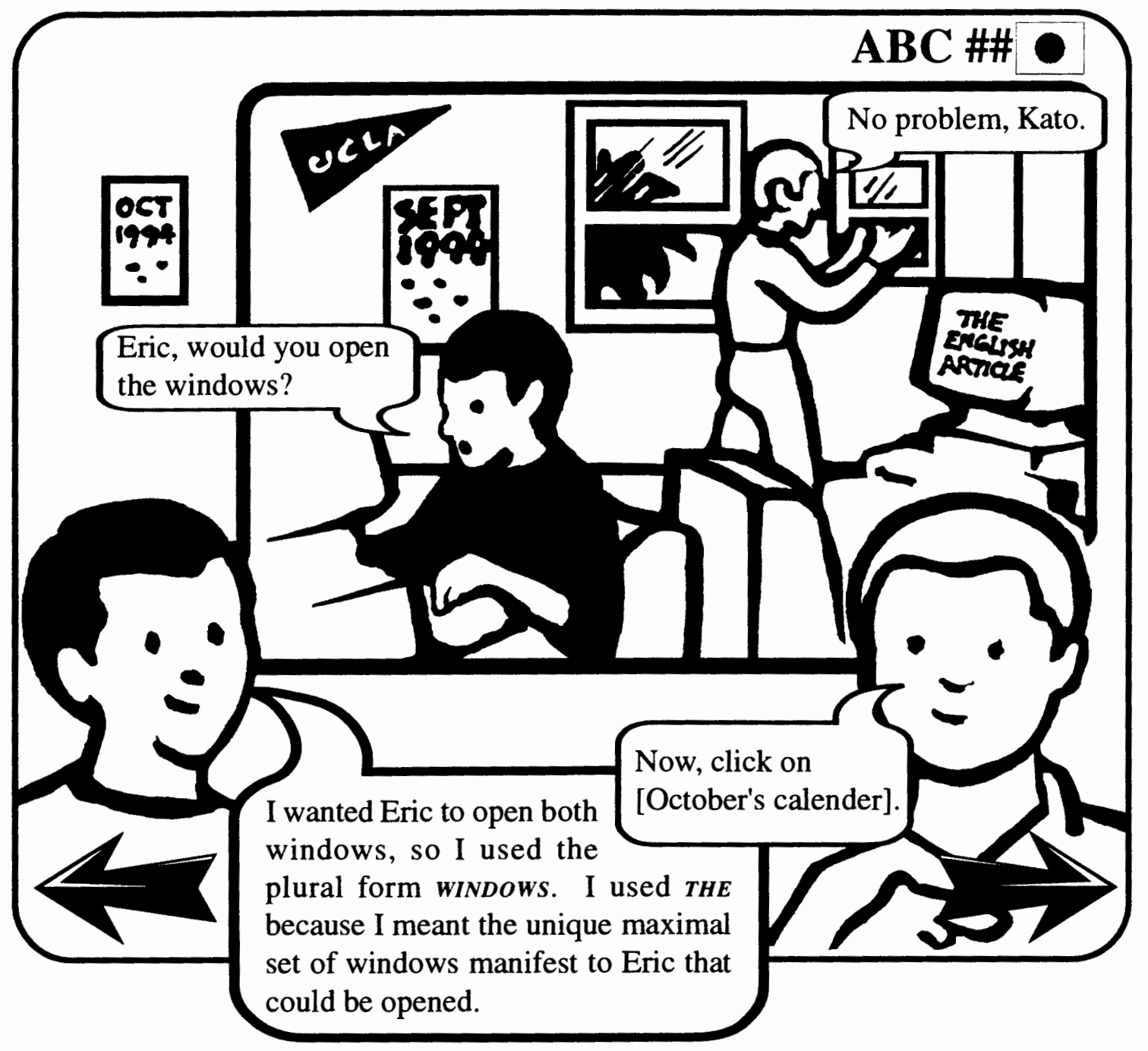




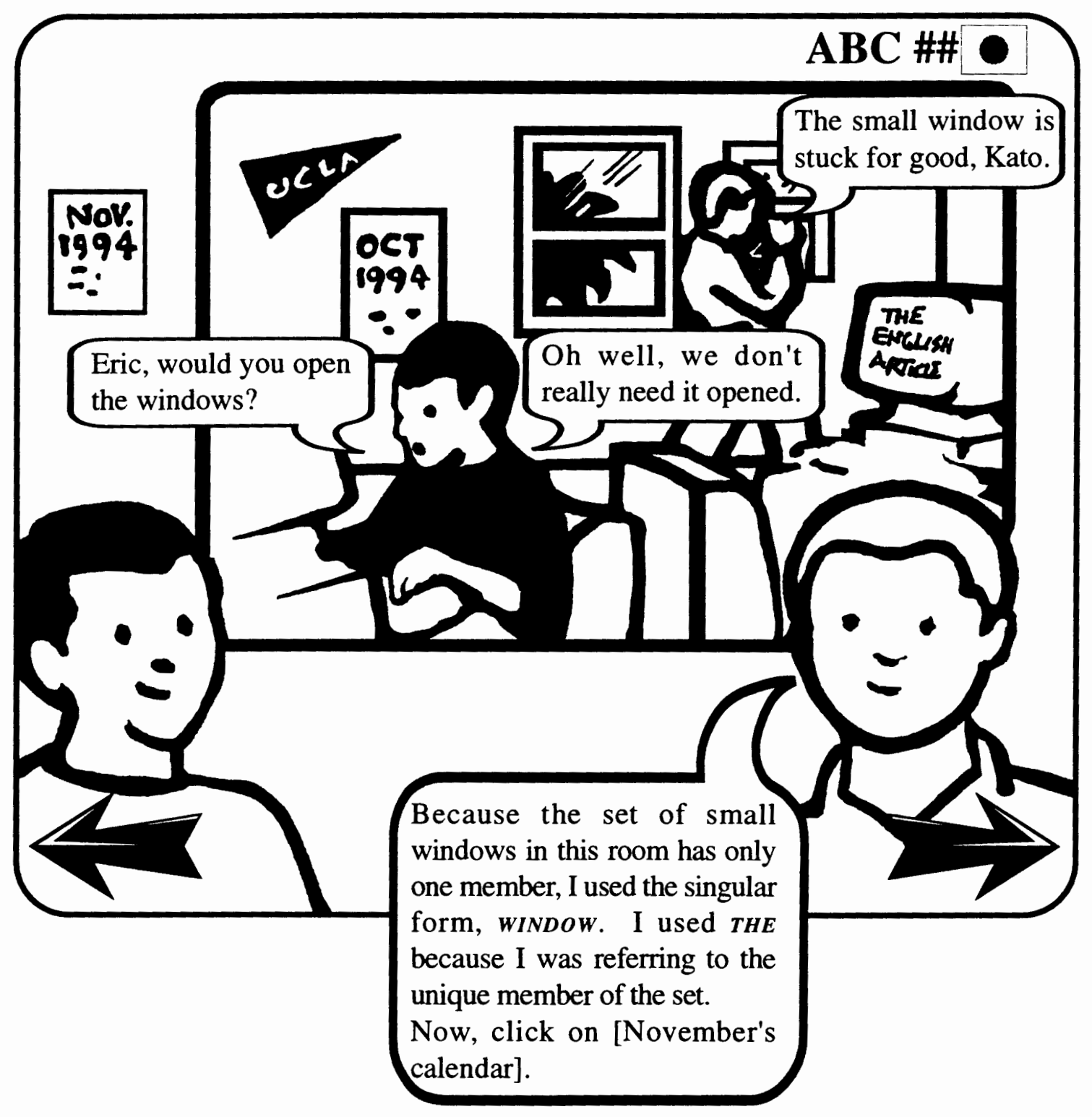




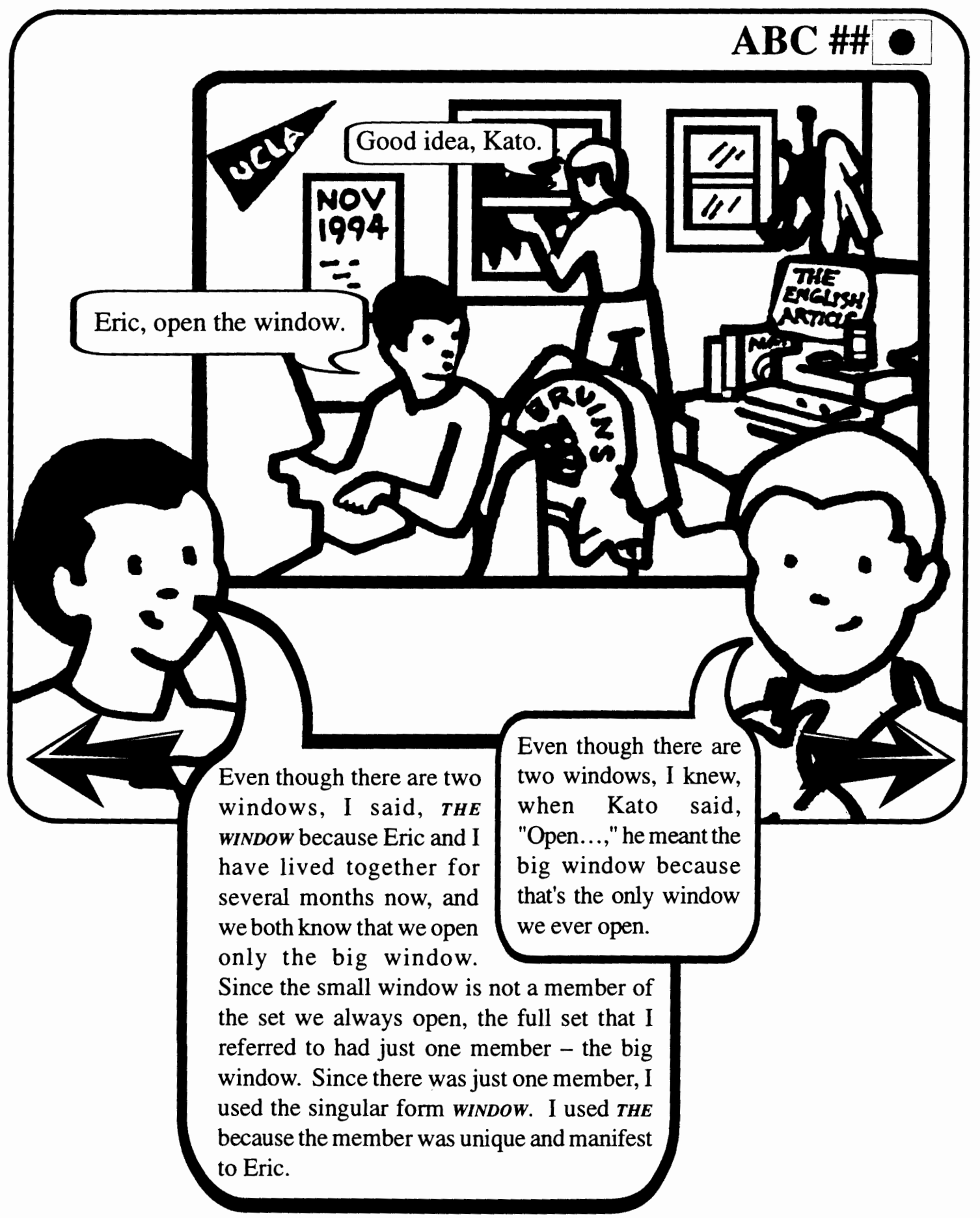




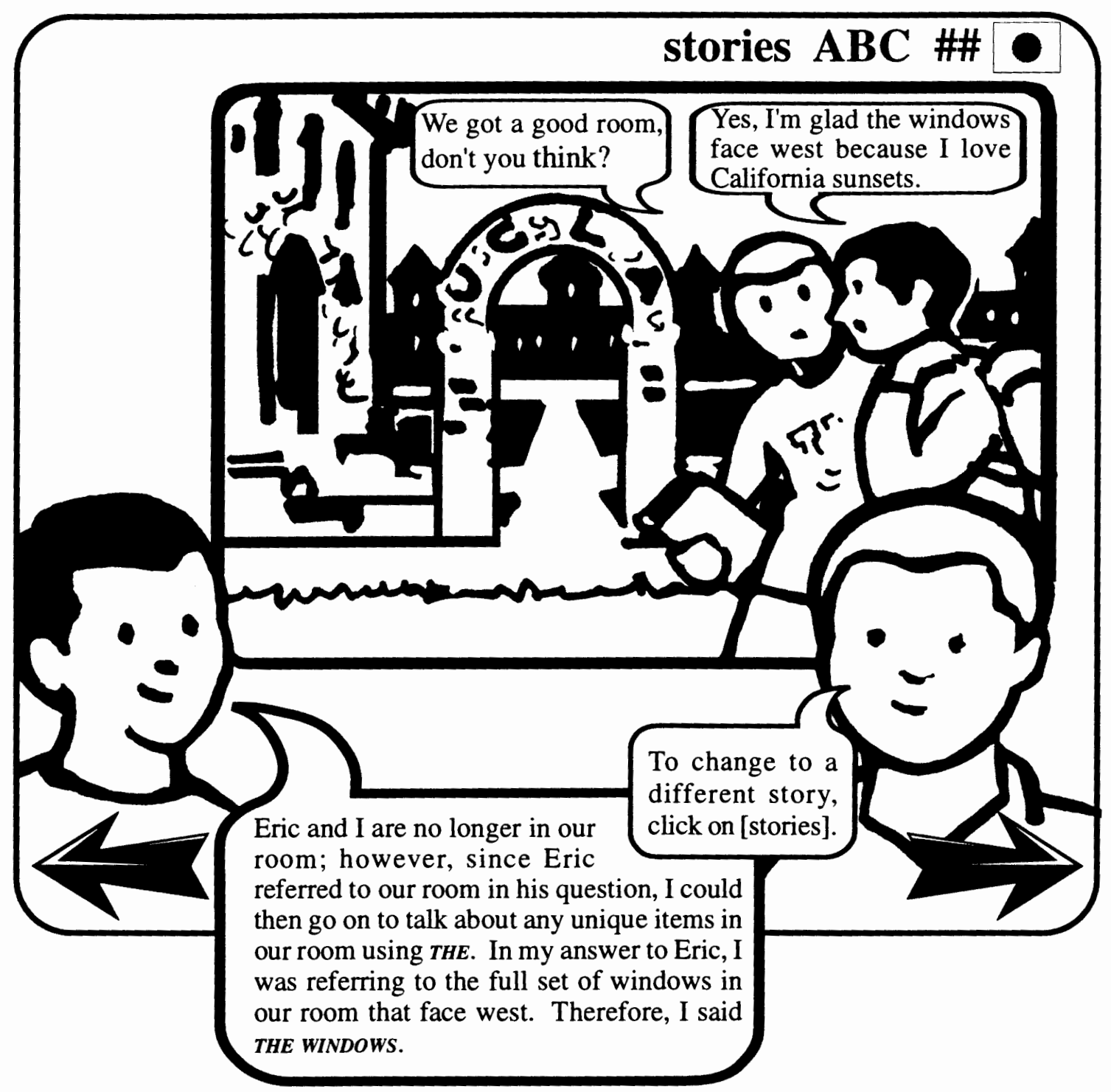




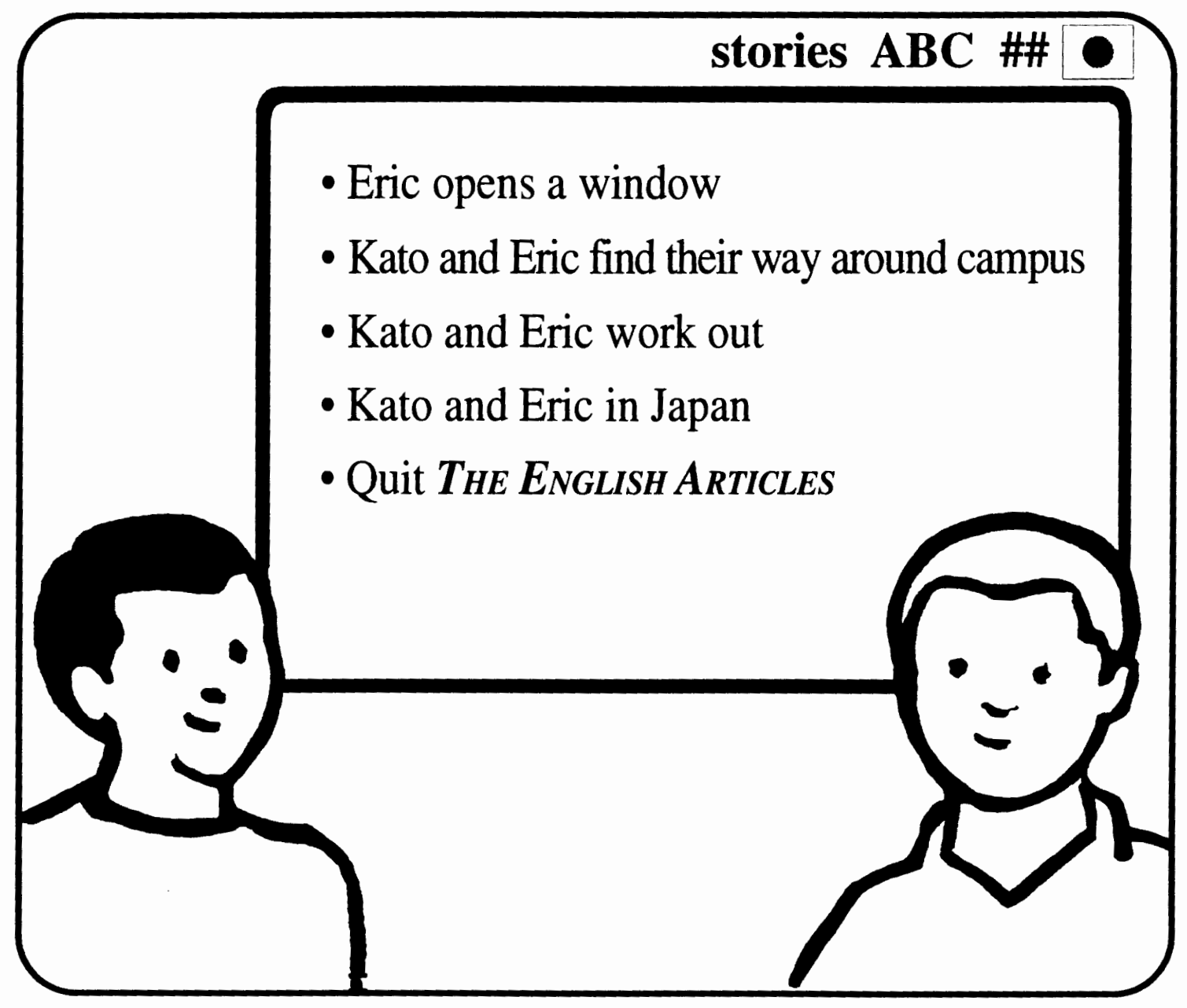


CHAPTER V

OTHER DESIGN ASPECTS OF THE TUTORIAL

I tried to learn articles, but it was impossible, so now I never use any! They are magic, and only Americans know magic trick. (Yasuhiro Misaki, personal communication, 1989).

This student, Yasuhiro, earned a score of 550 on the Test of English as a Foreign Language (TOEFL), a score high enough to earn him entrance to Stanford University's School of Business. The following prototype for a computerized tutorial was designed with Yasuhiro in mind as the typical user. The user would be intelligent, advanced in English, exasperated with the article system yet still curious about how it works.

The tutorial consists of a series of short "stories" featuring two characters, Kato and Eric, who are roommates at UCLA. All uses of the articles are non-generic. The uses are contextualized in these stories in order to capture past shared knowledge, and shared recent discourse and experience of the two characters. The emphasis is not on forms (mass, singular, plural) but on what John Hawkins called "pragmatic sets" in the real world. These, along with uniqueness, and the conversational implicatures 
described in Hawkins' theory are explained every time a character uses an article.

Unlike most English textbooks, which tend to simplify explanations to suit students' readering level, this tutorial uses advanced English syntax and terminology in its explanations. This advanced level should not be an obstacle to any user since Japanese translations are available at any time through a command option. The sole focus of the tutorial is article usage, not readability.

Wherever possible, "click objects" in the screen margins may alter the context of an utterance. When a user clicks an object, the change in context may cause a character to change his choice of article in the same sentence frame. This interactive aspect of the tutorial is crucial to showing how the articles are dependent on contexts wider than a sentence.

STORY: "Kato and Eric Find Their Way Around UCLA"

FRAME: Kato and Eric are leaving their dorm room. SMALL ERIC: "Let's go to the bookstore--I need to buy my Algebra II textbook."

BIG ERIC: I said the bookstore because each university has a unique bookstore where students buy their textbooks. Since the P-set of my utterance is a linguistic community (the university campus), my use of the can refer unambiguously to the unique UCLA campus bookstore. [P-set = Linguistic Community; +manifest +unique; the induces 
conventional implicature (there is a subset of entities, or bookstores, in the universe of discourse which is mutually manifest to speaker and hearer and within which the referent, bookstore, exists and is unique. The hearer should locate it)].

FRAME: Eric and Kato are walking across the campus. A stranger, who appears to be a student, is walking toward them.

SMALL KATO: "Let's ask this student where the bookstore is." SMALI KATO: "DO you know where the bookstore is?" STUDENT: "You must mean the UCLA bookstore. No, I don't, but I know where a bookstore is; you could go there and ask for directions to the bookstore."

BIG STUDENT: I said a bookstore because I meant not the unique UCLA textbook bookstore. Because I am on a campus, the definite article would be expected with the word bookstore. Since I have instead used a, my referent is unambiguously another bookstore, not the UCLA bookstore. [Pset $=$ Linguistic Community; Because the could have been used (the bookstore being +manifest and tunique), use of a Q-implicated (made the strongest statement consistent with a speaker's knowledge) not the since $a$ and the are on a horn scale, <the, a>]. SMALL ERIC: "Thanks anyway." FRAME: The stranger goes on his way as Eric and Kato approach a taco cart. 
SMALL ERIC: "Ummm ...I need a burrito."

BIG ERIC: I said a burrito because the P-set is the set of burritos on the cart. By using a when there are many burritos, I am implying one of the burritos. The could not have been used; therefore, since a P-set exists in which burrito could exist, use of a I-implicates (enriches to) one of the].

$[\mathrm{P}$-set $=$ Immediate Situation; +manifest -unique; use of a Iimplicates (enriches to) one of the].

FRAME: Eric and Kato are walking along carrying their burritos. Across the street, a football field, comes into view.

BIG ERIC: "Let's sit on the bleachers and watch the players practice."

BIG ERIC: Bleachers is always plural, so I used the plural form, bleachers. I said the bleachers rather than some bleachers because I meant the unique group of bleachers within the immediate situation of my utterance, the bleachers before us, manifest to Kato, which we could sit on. $[\mathrm{P}$-set = Immediate Situation; the +manifest +unique; the induces conventional implicature, i.e., there is a subset of entities, or bleachers, in the universe of discourse which is mutually manifest to speaker and hearer and within which the referent, bleachers, exists and is unique. The hearer should locate it]. 


\begin{tabular}{|l|l|l|}
\hline & SINGULAR & PLURAL \\
\hline ZERO-FORM & $1 .-$ & 2. bleachers \\
\hline ASOME - FORM & $3 .-$ & 4. some bleachers \\
\hline THE - FORM & $5 .-$ & 6. the bleachers \\
\hline
\end{tabular}

CLICK $A B C$ :

2. Bleachers are uncomfortable.

4. Some bleachers are steep.

6. When we get to the stadium, let's climb to the top of the bleachers.

CLICK OBJECT: DELIVERY VAN

FRAME: A delivery van obstructs Kato's view of the football field and the bleachers across the street.

SMALL KATO: "What bleachers?"

FRAME: The delivery van moves out of the frame.

SMALL KATO: "Oh, the bleachers over there."

BIG KATO: I said, "What bleachers?" because Eric made a

reference (the bleachers) that was not manifest to me--my view of the bleachers was obstructed by the van. [The P-set intended by the speaker (Immediate Situation) could not be correctly assessed by the hearer]. When the van moved away, I realized that Eric meant the bleachers that were visible, across the street. $[\mathrm{P}$-set $=$ Immediate Situation; +manifest tunique; the induces conventional implicature].

FRAME: Eric and Kato are again walking on the campus. SMALL ERIC: "I'm beginning to wonder if this school has a bookstore!" 
BIG ERIC: I said a bookstore because the verbs have and be actually define the membership of the relevant objects within a pragmatic set. They assert what the definite article presupposes, that certain objects exist within a Pset. In this case, the P-set is this school. Use of has asserts that bookstore is a unique member of this pragmatic set.

FRAME: Up ahead, a sign says, "Pegasus Books." SMALL ERIC: "Look! A bookstore!" BIG ERIC: I said a bookstore because I was directly referring to NOT the unique campus bookstore. $[P$-set $=$ Immediate Situation; +manifest tunique; the could be used; therefore, a Q-implicates not the]. SMALL KATO: "But it's the wrong one." CLICK OBJECT: BOOKSTORE SMALL ERIC: "Look! The bookstore!" BIG ERIC: I said the bookstore because I was directly referring to the unique campus bookstore. [P-set $=$ Immediate Situation; +manifest +unique; the induces conventional implicature].

FRAME: The former Pegasus Bookstore is now called The UCLA Bookstore.

FRAME: Eric and Kato are walking away from the bookstore. Kato is carrying an algebra book. SMALI ERIC: "Let's go to the library." 
BIG ERIC: This reference, the library, is just like the bookstore. Campuses always have a library. Since I am on a campus, my use of the library refers unambiguously to the unique UCLA undergraduate library, not to the Los Angeles Public Library or some other library. $\quad[$ P-set $=$ Linguistic Community; +manifest +unique; the induces conventional implicature] .

FRAME: Kato and Eric are studying at a library table. SMALI KATO: "Kato, I'm going back to the room to get my biology book."

BIG KATO: I said the room because the P-set is the set of rooms, known to my hearer, Eric, that contains my biology book. This set of rooms contains one member--our unique dormitory room. The only article possible is the. If I had said I am going back to a room to get my biology books, I would have been referring to not our dormitory room, and Eric would have wondered what room I was referring to. [Pset $=$ Linguistic Community; +manifest +unique; the induces conventional implicature].

SMALI KATO: "The syllabus of my math course is on my desk. I'll go with you."

BIG KATO: I said the syllabus because the following genitive, of my math course, created an NP, the syllabus of my math course, that defined the P-set within which the referent was unique and manifest. $[\mathrm{P}$-set $=$ Defined by 
Modifier; +manifest +unique; the induces conventional implicature].

FRAME: Kato and Eric exiting the Iibrary.

FRAME: Kato and Eric at the door of their room. SMALL ERIC: "Oh no, I think I left my keys on the bleachers."

BIG ERIC: I said the bleachers because Kato and I shared the experience earlier today of sitting on bleachers at the football field. By saying the bleachers I am unambiguously referring to that unique set of bleachers where I could have left my keys. $\quad[\mathrm{P}-\mathrm{set}=$ Previous Discourse; +manifest tunique; the induces conventional implicature]. FRAME: Eric running down the hallway. SMALL PASSERBY: "Where is he going?" SMALI KATO: "He left his keys on some bleachers." BIG KATO: I said some bleachers rather than the bleachers because this passerby does not know about the unique maximal set of bleachers where Eric has left his keys; some (the plural version of a) is the correct choice. [P-set $=$ none for this hearer; -manifest -unique; some is not enriched to some of the ].

\section{THE END}

\section{STORY: "Kato Works Out"}

FRAME: A side view of Kato jogging on a treadmill.

FRAME: TOp view of the treadmill (Kato's view) from where we see a printed message at the head of the walking platform. 
It reads, "This treadmill is designed to provide quiet, smooth operation for aggressive workouts. A powerful motor delivers efficient operation for serious exercise programs. The sturdy handrail is securely mounted to provide support on the wide, smooth walking surface. The user-friendly console permits continuous monitoring of electronic functions. An adjustable elevation mechanism adds versatility to any workout program." BIG KATO: The writer of this advertisement knew that to read it, the reader would have to stand so that some parts of the treadmill were visible and others were not. All of the parts mentioned with the would be unique and visible to the reader (they would be manifest); all the parts mentioned with a would be unique but hidden from the reader (they would not be manifest]: [P-set = Immediate Situation; +manifest and + uniques = the handrail, the surface, the console; -manifest and +uniques = an elevation mechanism, a motor; all uses of the induce conventional implicature; all uses of a].

FRAME: We see the side view again. Now Eric has walked into the frame and is watching Kato.

SMALL ERIC: "Kato, you should increase the speed." BIG ERIC: I used the speed because speed is unique in the immediate situation (of Kato's jogging on the treadmill). Other uniques in this situation are the elevation and the 
distance. $[\mathrm{P}$-set $=$ Bridging; +manifest +unique; the Iimplicates the speed of the treadmill].

SMALL KATO: "No thanks, $4 \mathrm{mph}$ is a good speed for me." BIG KATO: I used a good speed because the verbs have and be define the membership of the relevant objects within a pragmatic set. They assert what the definite article presupposes, that certain objects exist within a P-set. In this case, the $\mathrm{P}$-set is the speeds that are good for me. Within that set, use of is asserts that $4 \mathrm{mph}$ is a member. CIICK \#\# :

\begin{tabular}{|l|l|l|}
\hline & SINGULAR & PLURAL \\
\hline ZERO-FORM & 1. speed & 2. speeds \\
\hline ASOME - FORM & 3. a speed & 4. some speeds \\
\hline THE - FORM & 5. the speed & 6. the speeds \\
\hline
\end{tabular}

CIICK ABC:

1. People today expect to travel with great speed.

2. Speeds of over $90 \mathrm{mph}$ are harmful to your car's engine.

3. A walking speed of $3.5 \mathrm{mph}$ is good for the heart.

4. Some speeds make the parts of this motor vibrate.

5. The distance to the moon is measured by the speed of light.

6. Each year, Olympic runners break the speeds of previous runners.

FRAME: Kato and Eric trade places: Eric jumps onto the treadmill and turns up the speed. A clock appears on the wall and quickly moves ten minutes. Now Eric is exhausted 
but still running. In the background is a stack of folded towels.

SMALL ERIC: "Would you get me a towel."

BIG ERIC: The P-set contains all the towels in the stack in this room. I said a towel because a conversationally implicates one of the towels before us.[P-set = Immediate Situation; +manifest -unique; a I-implicates (enrich to) one of the].

CLICK OBJECT: TOWEL ON ATHLETIC BAG

FRAME: The stack of towels remains, but there also appears a single towel atop an athletic bag.

SMALL ERIC: Eric says, "Would you get me the towel?"

BIG ERIC: I said the towel because I was referring to the towel that kato could get for me that is unique--the towel on the athletic bag.

CLICK OBJECT: TOWEL ON CHAIR

FRAME: Now there is a stack of towels, a single towel on an athletic bag, and a towel on a hook on the wall.

ERIC: "Would you get me the towel on the wall?"

ERIC: The P-set is defined by the prepositional phrase on the wall. Since the towel in the P-set of towels on the wall is unique and manifest, I said the towel. If I had said "Get me the towel," Kato would not have known whether I meant the towel on the athletic bag or the towel on the wall. $[\mathrm{P}$-set $=$ Defined by Modifier; +manifest +unique; the induces conventional implicature]. 
FRAME: Kato hands Eric a towel. Eric mops his face and drapes the towel over the railing. Kato exits the scene. Eric follows.

KATO, OFF SCREEN: "DOn't forget the towel."

FRAME: An arm reaches back and grabs the towel.

BIG KATO: The P-set (towels that should not be forgotten) contains one member, so I used the singular form, towel. I used the because this towel is manifest to Eric--he just touched it, spoke about, and saw it--and because it is unique. $[P-s e t=$ Previous Discourse; +manifest +unique; the induces conventional implicature].

CLICK \#\#:

\begin{tabular}{|l|l|l|}
\hline & SINGULAR & PLURAL \\
\hline ZERO-FORM & 1. - & 2. towels \\
\hline ASOME - FORM & 3. a towel & 4. some towels \\
\hline THE - FORM & 5. the towel & 6. the towels \\
\hline
\end{tabular}

THE END

STORY: "Kato and Eric Go Camping"

FRAME: Twilight. Kato and Eric resting by a lake in the mountains.

FRAME: Eric's backpack is open. A trail map sticks out of the top.

SMALL KATO: "Could I see the trail map?"

BIG KATO: I said the trail map because I was referring to the unique map immediately in front of us, in the immediate situation of the utterance. $[$ P-set = Immediate Situation; +manifest +unique; the induces conventional implicature] . 
CLICK OBJECT: BACKPACK

FRAME: Eric's backpack is now closed.

SMALI KATO: "What's in your backpack?"

SMALI, ERIC: "I have a flashlight, a compass, a trail map, and some food."

BIG ERIC: I used a and some with these items because they were not manifest to Kato. Only manifest (and unique) items can take the.

SMALL KATO: "Could I see the trail map?"

BIG KATO: I said the trail map because the map was unique in Eric's pack (remember, Eric said a trail map not some trail maps) and because it was manifest to both of us, having been mentioned in the previous discourse when Eric said I have a trail map. [P-set = Previous Discourse; +manifest +unique; the induces conventional implicature]. FRAME: Eric hands Kato the trail map.

SMALL KATO: "The trail that we are on now, ends at a lookout."

BIG KATO: I said the trail because the relative clause that we are on now names the p-set (trails we are on now) within which our trail is unique and manifest. I said a lookout because the referent, lookout, was not manifest to Eric before my mention of it. [P-set = Defined by Modifier; +manifest +unique; the induces conventional implicature]. SMALL ERIC: "I hear an OwI." 
BIG ERIC: I said an owl because I don't believe that Kato heard the owl. In other words, I don't believe it was manifest to Kato.

CLICK OBJECT: OWL [sound of an OWI]

SMALI KATO: "The owl sounds close by."

BIG KATO: I said the owl because I guessed that Eric probably heard the owl sound I just heard. I guessed that the sound was manifest to Eric and I assumed (rightly or wrongly) that the sound came from the same (unique) owl as before. $[\mathrm{P}$-set $=$ Previous Discourse; +manifest +unique; the induces conventional implicature].

SMALL ERIC: "I wonder if the moon will be out tonight." BIG Eric: I said the moon because I was referring to the earth's unique moon. [P-set = Linguistic Community;

+manifest +unique; the induces conventional implicature]. CLICK OBJECT: $M O O N$

FRAME: Darkness with full moon rising.

SMALL KATO: "Look, there's a full moon tonight." BIG KATO: I said a full moon because a follows existential there.

CLICK OBJECT: SUN

FRAME: It is daybreak with pale moon sinking in the west. SMALI ERIC: "The moon is gone."

BIG ERIC: I said the moon because I was referring to the earth's unique moon. [P-set = Linguistic Community; +manifest +unique; the induces conventional implicature]. 
SMALI KATO: "But look, there's the moon and the sun, too." BIG KATO: In this sentence there is used to "point to" the moon rather than to state the existence of the moon; therefore, so I used the [earth's unique] moon, not a moon. CLICK \#\# :

\begin{tabular}{|l|l|l|}
\hline & SINGULAR & PLURAL \\
\hline ZERO-FORM & 1. - & 2. moons \\
\hline ASOME-FORM & 3. a moon & 4. some moons \\
\hline THE-FORM & 5. the moon & 6. the moons \\
\hline
\end{tabular}

CIICK ABC:

1.

2. Moons that have halos predict rain.

3. A full moon means more crime in the city.

4. Some moons have smiling faces.

5. The moon is rising.

6. The moons I like best are fragile crescents. SMALL ERIC: "I hope I catch a trout today." BIG ERIC: I said a trout because the P-set is all the trout in the lake that I hope to catch. A conversationally implicates one of the. $[\mathrm{P}$-set $=$ Bridging; +manifest -unique; a I-implicates one of the]. SMALL KATO: "The trout I catch will be my breakfast." BIG KATO: I said the trout because the p-set is the particular trout in the lake that I will catch. It is a one-member, unique and manifest $\mathrm{P}$-set. $\quad[\mathrm{P}$-set $=$ Defined by Modifier; +manifest +unique; the induces conventional implicature]. 
FRAME: Eating their trout.

SMALL ERIC: "There's nothing like a fresh trout for breakfast."

BIG ERIC: A follows existential there.

THE END

\section{STORY: "Kato and Eric in Japan"}

FRAME: Kato and Eric in a kimono shop. A clerk is showing them a kimono.

SMALL SALESCLERK: "Would you like to see an obi for this kimono?"

BIG SALESCLERK: I said an obi because a wearer may choose any obi to go with a kimono. A kimono does not have a unique obi designed just for it. If there had been a unique obi just for that kimono, I would have said the obi. [P-set = Defined by Modifier; +manifest -unique; an I-implicates one of the obis].

FRAME: Kato and Eric leaving the shop with a package. SMALL KATO: "I really want to go to a snow festival." BIG KATO: I said a snow festival because I knew there were two--one at O-dori Park and one at Makomanai. My use of a meant one of the. $[\mathrm{P}-$ set $=$ Linguistic Community; +manifest -unique; a I-implicates one of the].

SMALL ERIC: "After the snow festival, let's pick up an English-language newspaper."

BIG ERIC: I said an English-language newspaper because there are approximately four different English-language dailies to 
choose from. [P-set = linguistic community; +manifest -unique; a I-implicates one of the].

SMALI KATO: "When we return to Tokyo, let's stop in at the the JNTO (Japan National Tourist Organization) Center." BIG KATO: I said the JNTO because, although there are several JNTO offices in Japan, there is only one JNTO Center in Tokyo. Since this office is unique to the city of Tokyo, it is unique in its $P$-set. $[P$-set $=$ city of Tokyo; +manifest +unique; the induces conventional implicature SMALI ERIC: "Yes, maybe the JNTO guides can tell us how to get to the Ibusuki jungle bath." BIG ERIC: I said the Ibusuki jungle bath because there is one such jungle bath in Ibusuki; therefore, it is unique in this modifier-defined P-set. $[\mathrm{P}$-set = Defined by Modifier; +manifest +unique; the induces conventional implicature.] 
CHAPTER VI

CONCLUSION

Authors of the performance studies frequently mentioned the problem of being unable to determine, in cases where more than one article fit a sentence frame, whether the article chosen matched the student's intended referent or not. A similar problem may arise when students decode. When there seems to be more than one possibility, students may not know which entity an article is referring to because they do not know how the articles function, or what they "mean." The aforementioned tutorial addresses the decoding problem by exhaustively explaining the choices that English speakers make in given situations. It shows how speakers silently exploit mutually manifest, real-world situations, cordoned off as "P-sets," to establish the uniqueness of entities. Once uniqueness is mentally established, they then use articles to induce implicatures and thereby refer unambiguously.

The tutorial is designed to emphasize these pragmatic aspects of article usage. Whenever possible, contexts are manipulated to reflect the contrasting uses of the and a in the same sentence frame. A speaker's choice of article 
is explained from the speaker's point of view as an actor's "aside", rather than from a third-party, or author's perspective. Traditional terms such as specific and definite, whose Japanese counterparts may connote different meanings, are avoided. And, since the target structure is just the articles rather than other vocabulary, a "command" option offers Japanese translation of all text. Mechanical aspects such as mass, singular, and plural forms are also handled as command options. The culture-bound aspect of the uniqueness of noun phrases is illustrated with examples situated in Japanese culture.

Although the tutorial presents a variety of situational contexts for definite and indefinite reference, it is, as it stands, only a prototype. To have serious pedagogical value, the number of examples would need to be greatly increased. In addition, a complete tutorial would need an intensive section on premodified noun phrases, an area that is difficult for Japanese students (Iwasaki 1990) and one that has been almost universally neglected by textbooks. That section could be incorporated relatively easily, as it would likely resemble a traditional textbook drill.

Since the tutorial emphasizes decoding, the question arises whether students could ever learn to encode, or actually produce articles on-line. The rate of speed used for speech would seem to make the feat impossible. Yet, as complicated as the articles are, students may still learn to 
produce them on-line if they first learn to interpret the articles they hear in terms of uniqueness relative to mutually manifest p-sets and the implicatures that the articles induce. By using these tools, and by taking the time to reflect on sentences recently heard or seen, students may arrive at the correct interpretations. Once they learn to interpret correctly when they decode, they may eventually learn to encode correctly as well.

In recent years, the field of TESOL has put forth research papers ending with "pedagogical implications, " or advice on how to improve teaching materials based on findings. This project has been a response to those papers' recommendations and to the data of the performance studies which laid the groundwork for, what I hope, is an improved English article system for Japanese speakers. To the extent that the field of second-language learning adapts theories from other domains--psychology and linguistics--to the practical goal of teaching a second language, the field is an applied science. This project has undertaken to adapt recent discoveries in pragmatics to the practical problem of teaching article usage. Its efforts, as such, fall within the scope of second-language learning as an applied science. 


\section{REFERENCES}

Austin, J.L. 1955. How to Do Things with Words. London: Oxford University Press.

Brown, R. 1973. A First Language:The Early Stages. Cambridge, Mass: Harvard University Press.

Christopherson, P. 1939. The Articles: A Study of Their Theory and Use in English. London: Oxford University Press.

Clark, H. and S. Haviland. 1977. "Comprehension and the the Given-New Contract." In Freedle, R. (Ed.). Discourse Production and Comprehension. Hillsdale, New Jersey: Erlbaum.

Clark, H.H. and C.R. Marshall. 1981. "Definite Reference and Mutual Knowledge." In Joshi, A., Webber, B. and I. Sags (Eds.). Elements of Discourse Understanding. Cambridge: Cambridge University Press.

Cruse, D.A. 1980. "Review of Hawkins (1978)." Journal of Linguistics, 16: 308-316.

Declerck, R. 1987. "Definiteness and Inclusive Reference." Journal of Literary Semantics, 16: 12-29.

Du Bois, J.W. 1980. "Beyond Definiteness: The Trace of Identity in Discourse." In Chafe,W.L. (Ed.). The Pear Stories: Cognitive, Cultural, and Linguistic Aspects of Narrative Production (Volume III Advances in Discouse Processes). Norwood, New Jersey: Ablex.

Dulay, H. and M. Burt. 1974/1983. "Goofing: An Indicator of Children's Second Language Strategies." In Gass, S.and L.Selinker (Eds.). Language Transfer in Language Learning. Rowley, Mass.: Newbury House.

Eckman, F.R. 1977. "Markedness and the Contrastive Analysis Hypothesis." Language Learning, 27: 315-330. 
Fathman, A. 1977. "Similarities and Simplification in the Interlanguage of Second Language Learners." In Corder, S. P. and E. Roulet (Eds.). Actes du 5eme colloque de Iinguistique appliquée de Neuchâtel. Neuchâtel: Faculté des Lettres.

Gil, D. 1987. "Definiteness, Noun Phrase Configurationality, and the Count-Mass Distinction." In Reuland, E.J. and A.G.B. ter Meulen, (Eds.). The Representation of (In)Definiteness. Cambridge, Mass.: MIT Press.

Gilbert, G. 1983. "Transfer in Second Language Acquisition." In Anderson, R. (Ed.). Pidginization and Creolization as Language Acquisition. Rowley, Mass.: Newbury House.

Goodman, K. and S. Nirenburg (Eds.). 1991. The KBMT Project: A Case Study in Knowledge-Based Machine Translation. San Mateo, Calif.: Morgan Kaufmann.

Grannis, O.C. 1972. "The Definite Article Conspiracy in English." Language Learning, 22(2): 275-289.

Grice, H.P. 1975. "Logic and Conversation." In Cole, P. and J.Morgan (Eds.). Syntax and Semantics: Vol 3. New York: Academic.

Hawkins, J.A. 1978. Definiteness and Indefiniteness:A Study in Reference and Grammaticality Prediction. Atlantic Highlands, New Jersey: Humanities.

Hawkins, J.A. 1991. "On (In)Definite Articles: Implicatures and (Un)Grammaticality Prediction." Journal of Linguistics, 27: 405-442.

Iwasaki, N. 1990. Analysis of English Articles Used by Japanese Students. Unpublished M.A. thesis, Portland State University.

Jespersen, O. 1966. (originally published 1933). Essentials of English Grammar. University of Alabama Press.

Kempf, M. 1975. "A Study of English Proficiency Level and the Composition Errors of Incoming Foreign Students at the University of Cincinnati 1969-1974." Unpublished Phd. dissertation, Ohio State University.

Kempson, R. 1988. "Grammar and Conversational Principles." In Newmeyer, F.(Ed.). Linguistic theory: extensions and implications (Linguistics: The Cambridge Survey, II). Cambridge: Cambridge University Press. 
Klein, E. 1980. "Locating the Articles." Linguistics, 18: 147-157.

Koizumi, K. 1989. Eigo no naka no fukusuu to kanshi. [Plurality and articles in English]. Tokyo: Japan Times.

Kubo, M. 1988. On the Realization of Definiteness. Master's thesis. University of Washington.

Lacey, A. 1977. "Rules in the Teaching of the English Articles." English Language Teaching Journal, 32: 3337 .

Larsen-Freeman, D. 1976. "The Acquisition of Grammatical Morphemes by Adult ESL Students." TESOL Quarterly, 9 (4) : 409-413.

Larsen-Freeman, D. and M. Long. 1991. An Introduction to Second Language Acquisition Research. New York: Longman.

Leech, G.N. 1983. Principles of Pragmatics. New York: Longman.

Levinson, S.C. 1983. "Pragmatics and the Grammar of Anaphora: a Partial Pragmatic Reduction of Binding and Control Phenomena." Journal of Linguistics, 23: 379434 .

Master, P. 1987. A Cross-linguistic Interlanguage Analysis of the Acquisition of the English Article System. Unpublished Phd. dissertation, UCLA.

Master, P. 1990. "Teaching the English Articles as a Binary System." TESOL Quarterly, 24:(3): 461-478.

Maratsos, M. 1976. The Use of Definite and Indefinite Reference in Young Children. Cambridge: Cambridge University Press.

McCawley, J. 1981. Everything that linguists have always wanted to know about logic but were ashamed to ask. Chicago: University of Chicago Press.

Molhot, G. 1980. "Contributions of the Definite Article to the Coherence of Discourse." TESOL Newsletter, 14(16).

Nakai, K. 1994. Excerpt from unpublished course paper. Clackamas Community College, Oregon City, OR. 
Newmeyer, F. 1986. Linguistic Theory in America, 2nd ed., San Diego, Calif: Academic Press.

Oda, M. 1990. Eibunpo gakushu no kiso [Foundations of the study of English grammar]. Tokyo: Kenkyusha.

Odin, T. 1989. Language Transfer. Cambridge: Cambridge University Press.

Oller, J. and E. Reddding. 1971. "Article Usage and Other Language Skills." Language Learning, 20: 183-89.

Pica, T. 1983. "The Article in American English: What the Textbooks Don't Tell Us." In Wolfson, N. and E. Judd, (Eds.). Sociolinguistics and Language Acquisition. Rowley, Mass.: Newbury House.

Ringbom, H. 1976. "What Differences Are There Between Finns and Swedish-speaking Finns Learning English?" In Ringbom, H. and R. Palmberg (Eds.). Errors Made by Finns and Swedish-Speaking Finns in the Learning of English. Abo, Finland: Department of English, abo Akademi .

Russell, B. 1905. "On Denoting." Mind 14: 479-493.

Schegloff, E.A. 1972. "Notes on a Conversational Practice: Formulatting Place." In Sudnow, D.N. (Ed.). Studies in Social Interaction. New York: The Free Press.

Searle, J.R. 1969. Speech Acts. Cambridge University Press.

Stenning, K. 1976. "Articles, Quantifiers, and Their Encoding in Textual Comprehension." In Freedle, R.O.(Ed.). Discourse Production and Comprehension. Hillsdale, New Jersey: Erlbaum.

Sperber, D. and D.Wilson. 1986. Relevance: Communication and Cognition. Cambridge, Mass: Harvard University Press.

Strawson, P.F. 1950. "On Referring." Mind 59: 320-44.

Tawa, W. 1993. "Interpretation of Definiteness: With Special Reference to Japanese." Word 44(3): 379-397.

Thomas, M. 1989. "The Acquisition of English Articles by First-and Second-Language Learners." Applied

Pachainguistics, 10: 335-355. 
Thompson, I. 1987. "Japanese Speakers." In Swan, M. and B. Smith (Eds.). Learner English: A Teacher's Guide to Interference and Other Problems. Cambridge: Cambridge University Press.

Whitman, R.L. 1974. "Teaching the Article in English." TESOL Quarterly, 8(3): 253-262.

Yamada, J. and N. Matsuura. 1982. "The Use of the English Article Among Japanese Students." RELC Journal, 13(1): $50-63$.

Zobl, H. 1982. "A Direction for Contrastive Analysis: The Comparative Study of Developmental Sequences." TESOL Quarterly, 16: 169-183. 
APPENDIX A

SURVEY OF ESL TEXTBOOKS 
ESL TEXTBOOK SURVEY

\begin{tabular}{|c|c|c|c|c|c|c|}
\hline TITLE & $\begin{array}{c}\text { AUTHOR } \\
\text { PUBLISHER }\end{array}$ & DATE & $\begin{array}{l}\text { NUMBER } \\
\text { OF PAGES } \\
\text { IN } \\
\text { GRAMMAR } \\
\text { SECTION }\end{array}$ & $\begin{array}{l}\text { NUMBER } \\
\text { OF PAGES } \\
\text { ON } \\
\text { ARTICLES }\end{array}$ & $\begin{array}{l}\text { NUMBER } \\
\text { OF PAGES } \\
\text { THAT } \\
\text { CONTRAST } \\
\text { THE USES } \\
\text { OF THE, } \\
\text { A, AND } \oslash\end{array}$ & ADVICE \\
\hline $\begin{array}{l}\text { English Alive: } \\
\text { Grammar, Function, } \\
\text { and Setting }\end{array}$ & $\begin{array}{l}\text { Fingado and } \\
\text { Jerome } \\
\text { Little, Brown } \\
\text { and Co. }\end{array}$ & 1982 & 320 & 0 & 0 & 0 \\
\hline $\begin{array}{l}\text { Exploring Through } \\
\text { Writing: A Process } \\
\text { Approach to ESL } \\
\text { Composition }\end{array}$ & $\begin{array}{l}\text { Raimes } \\
\text { St. Martins }\end{array}$ & 1987 & 318 & 6 & 6 & $\begin{array}{l}\text { "A specific reference is known by the writer and by the reader } \\
\text { as something unique, specific, or familiar, or previously } \\
\text { identified to the reader....A nonspecific reference is not } \\
\text { identified by the writer and by the reader as something known, } \\
\text { unique, or familiar." }\end{array}$ \\
\hline $\begin{array}{l}\text { Focus: } \\
\text { An ESL Grammar }\end{array}$ & $\begin{array}{l}\text { Robinson } \\
\text { St. Martins }\end{array}$ & 1989 & $\overline{324}$ & 3.5 & 2.5 & $\begin{array}{l}\text { "Use the article the with a noun when both the speaker and the } \\
\text { listener know the specific thing(s) it is referring to. ... Use the } \\
\text { indefinite articles a, an, and some or no article to refer to } \\
\text { items that have not been mentioned or identified before. Use } \\
\text { the indefinite article if either the listener or the speaker does } \\
\text { not know the particular item. Indefinite articles are often used } \\
\text { to mention a noun for the first time." }\end{array}$ \\
\hline Skills in Sequence & $\begin{array}{l}\text { Friedmann } \\
\text { St. Martins }\end{array}$ & 1988 & 472 & 7 & 0 & 0 \\
\hline $\begin{array}{l}\text { Grammar in Context } \\
\text { Book Two }\end{array}$ & $\begin{array}{l}\text { Elbaum } \\
\text { Scott Foresman }\end{array}$ & 1986 & 317 & 0 & 0 & 0 \\
\hline
\end{tabular}




\begin{tabular}{|c|c|c|c|c|c|c|}
\hline $\begin{array}{l}\text { Grammar in Context } \\
\text { Book One }\end{array}$ & $\begin{array}{l}\text { Elbaum } \\
\text { Scott Foresman }\end{array}$ & 1989 & 364 & 19 & 4 & $\begin{array}{l}\text { "Indefinite Nouns. We use a/an to mean an indefinite one. } \\
\text { It is not important to know exactly which one. I have a book. I } \\
\text { need an eraser. } \\
\text { Specific Nouns. We use the for specific things. Both the } \\
\text { speaker and the listener know which one we are talking about. } \\
\text { We know exactly which one for one of the following reasons: } \\
\text { We share common experience, or there is only one in our } \\
\text { experience. We identified the noun before. We specify } \\
\text { exactly which one. } \\
\text { We use the...to talk about the group as a single unit. The } \\
\text { hammer is a useful tool. We can usually use the 'zero article' } \\
\text { and a plural noun, or a and a singular noun to express the } \\
\text { same idea. In this case we are talking about all the members of } \\
\text { the group or a typical member of the group. Hammers are } \\
\text { useful tools. A hammer is a useful tool. However, the sounds } \\
\text { more technical or scientific. } \\
\text { Abstract Nouns. For an abstract or general idea, we use the } \\
\text { 'zero article' Do your friends give you advice? We can modify } \\
\text { an abstract noun and make it specific. In this case we use the } \\
\text { Do you follow the advice of your friends?" }\end{array}$ \\
\hline $\begin{array}{l}\text { Grammar Plus: } \\
\text { A Basic Skills Course }\end{array}$ & $\begin{array}{l}\text { DeFilippo and } \\
\text { Mackey } \\
\text { Addison-Wesley }\end{array}$ & \begin{tabular}{|l|l}
1987 \\
\end{tabular} & 298 & .5 & 0 & 0 \\
\hline $\begin{array}{l}\text { How English Works: } \\
\text { A Grammar Handbook } \\
\text { with Readings }\end{array}$ & $\begin{array}{l}\text { Raimes } \\
\text { St. Martins }\end{array}$ & 1990 & 318 & 11 & 11 & $\begin{array}{l}\text { "Use the definite article the when a noun phrase...makes a } \\
\text { specific reference for your reader. The reader will know from } \\
\text { information contained in the text what actual person, thing, or } \\
\text { concept you are referring to.... We can also use the to refer to } \\
\text { something outside the written text when we know the reader's } \\
\text { own familiarity with the context will make the reference } \\
\text { specific. } \\
\text { When we refer to someone or something that will not be } \\
\text { actual and specific for the reader or listener, we do not use the. } \\
\text { Instead, we use...a or an...zero article...some." }\end{array}$ \\
\hline Perspectives 2000 & $\begin{array}{l}\text { Chamot, et al } \\
\text { Heinle and Heinle }\end{array}$ & 1992 & 179 & 0 & 0 & 0 \\
\hline
\end{tabular}




\begin{tabular}{|c|c|c|c|c|c|c|}
\hline $\begin{array}{l}\text { The Grammar } \\
\text { Handbook }\end{array}$ & $\begin{array}{l}\text { Feigenbaum } \\
\text { St. Martins }\end{array}$ & 1985 & 358 & 8 & 8 & $\begin{array}{l}\text { "The indefinite article has the meaning of one or singular; } \\
\text { therefore, it can be used only with singular nouns. } \\
\text { The definite article is used when the noun being referred to in } \\
\text { a statement is clear to the sender and receiver of a } \\
\text { message....[example] the is used because the noun was } \\
\text { referred to before...Context: a noun can be definite because of } \\
\text { the common understanding of the people involved in the } \\
\text { communication. Because they are living or thinking about the } \\
\text { same situation, they know what to expect there." }\end{array}$ \\
\hline $\begin{array}{l}\text { The English } \\
\text { Connection }\end{array}$ & $\begin{array}{l}\text { Fingado, et al } \\
\text { Little, Brown and } \\
\text { Co. }\end{array}$ & 1981 & 475 & 0 & 0 & 0 \\
\hline $\begin{array}{l}\text { The Elements of } \\
\text { English Grammar I }\end{array}$ & $\begin{array}{l}\text { Holschuh } \\
\text { St. Martins }\end{array}$ & 1991 & 305 & 5 & 5 & $\begin{array}{l}\text { "Indefinite articles are used in front of nouns to show that } \\
\text { the nouns are not identified. That is, the speaker and the } \\
\text { listener are not thinking about exactly the same item. } \\
\text { The definite article the is used in front of nouns to show that } \\
\text { the nouns are identified. That is, both the speaker and the } \\
\text { listener are thinking about exactly the same item.... Often, the } \\
\text { first time that a noun is mentioned, it indefinite. But the second } \\
\text { time...it becomes definite.... When a noun is identified by other } \\
\text { information in the same sentence, it is often definite...." }\end{array}$ \\
\hline $\begin{array}{l}\text { The Functions of } \\
\text { English Grammar II }\end{array}$ & $\begin{array}{l}\text { Holschuh } \\
\text { St. Martins }\end{array}$ & 1991 & 415 & 6 & 6 & $\begin{array}{l}\text { When a noun is used in an indefinite sense, it refers to an } \\
\text { object or a concept, but not to a specific object or concept that } \\
\text { is known to both speaker and the listener. When a noun is } \\
\text { used in a definite sense, it refers to a specific object or } \\
\text { concept that is known to both the speaker and the listener. } \\
\text { Both the speaker and the listener know the identity of the } \\
\text { noun...[which] can be established in many ways...a) previous } \\
\text { mention... b) a following identifying phrase...Be careful! A } \\
\text { phrase or clause that follows a noun does not always identify } \\
\text { it...c) shared knowledge... }\end{array}$ \\
\hline $\begin{array}{l}\text { The Advanced } \\
\text { Grammar Book }\end{array}$ & $\begin{array}{l}\text { Steer and Carlisi } \\
\text { Newbury House }\end{array}$ & 1991 & 390 & 14 & 1.5 & $\begin{array}{l}\text { The's] use indicates that the speaker...and listener share a } \\
\text { definite knowledge about the noun referred to....the noun has } \\
\text { been qualified by a prepositional phrase or adjective clause; } \\
\text { the noun has been previously specified; the noun refers to the } \\
\text { class or thing in general; there is a superlative; the noun is one } \\
\text { of a kind. }\end{array}$ \\
\hline
\end{tabular}




\begin{tabular}{|c|c|c|c|c|c|c|}
\hline $\begin{array}{l}\text { Visions: A Pre- } \\
\text { Intermediate } \\
\text { Grammar }\end{array}$ & $\begin{array}{l}\text { Lites and Lehman } \\
\text { Prentice-Hall } \\
\text { Regents }\end{array}$ & 1990 & 310 & 3 & .5 & $\begin{array}{l}\text { "Avan =we don't know which one. } \\
\text { Prepositional phrases make nouns specific.... Use the with } \\
\text { specific people or things... When there is only one person or } \\
\text { thing (the earth...) use the... The first time you say a noun, use } \\
\text { a an or no article. After the first time, use the." }\end{array}$ \\
\hline $\begin{array}{l}\text { English Structure in } \\
\text { Focus: Book One }\end{array}$ & $\begin{array}{l}\text { Davis } \\
\text { Newbury House }\end{array}$ & 1987 & 379 & 8 & 1.75 & $\begin{array}{l}\text { "We use the when both the speaker and the listener know } \\
\text { which item is meant....Study the use of the as you continue in } \\
\text { this book. You will find some other ways of knowing 'which."' }\end{array}$ \\
\hline $\begin{array}{l}\text { Basic English } \\
\text { Grammar }\end{array}$ & Azar & 1984 & 284 & 0 & 0 & 0 \\
\hline $\begin{array}{l}\text { Understanding } \\
\text { and Using English } \\
\text { Grammar } \\
\text { Second Edition }\end{array}$ & $\begin{array}{l}\text { Azar } \\
\text { Prentice-Hall }\end{array}$ & 1989 & 411 & 4 & 0.25 & $\begin{array}{l}\text { "indefinite nouns are actual things (not symbols) but they are } \\
\text { not specifically identified. In I ate a banana, the speaker is } \\
\text { not referring to 'this banana' or 'that banana you gave me.'...A } \\
\text { noun is definite when both the speaker and the listener are } \\
\text { thinking about the same specific thing. In thank you for the } \\
\text { banana, the speaker uses the because the listener knows } \\
\text { which specific banana the speaker is talking about... Use the } \\
\text { for the second mention of an indefinite noun." }\end{array}$ \\
\hline $\begin{array}{l}\text { A Competency-Based } \\
\text { Grammar }\end{array}$ & $\begin{array}{l}\text { Kirn, E. } \\
\text { Random House }\end{array}$ & 1989 & 180 & 7 & .5 & $\begin{array}{l}\text { "General statements usually contain nonspecific nouns. A } \\
\text { noun is nonspecific if you can't answer the question 'Which } \\
\text { one or ones?' Food contain calories. A calorie is a unit of } \\
\text { energy. A specific noun can be identified in a previous } \\
\text { sentence or in the same sentence. A noun is specific if you } \\
\text { can answer the question 'Which one or ones?' I avoid ice } \\
\text { cream because of the calories. (Which calories? The calories } \\
\text { in the ice cream). A noun mentioned for the first time is } \\
\text { nonspecific if there are more than one in the context. Do you } \\
\text { always keep a box of cookies on a shelf in a kitchen cupboard? } \\
\text { Sometimes a specific noun needs no identification because it } \\
\text { is clear from the context which one is meant. Look in the } \\
\text { refrigerator. (Which refrigerator? There's only one in the } \\
\text { context.)" }\end{array}$ \\
\hline $\begin{array}{l}\text { Developing Basic } \\
\text { Writing Skills in } \\
\text { English as a Second } \\
\text { Language }\end{array}$ & $\begin{array}{l}\text { Eichler } \\
\text { University of } \\
\text { Pittsburgh Press }\end{array}$ & 1981 & 166 & 0 & 0 & 0 \\
\hline
\end{tabular}




\begin{tabular}{|c|c|c|c|c|c|c|}
\hline $\begin{array}{l}\text { A Practical English } \\
\text { Grammar: } \\
\text { Fourth Edition }\end{array}$ & $\begin{array}{l}\text { Thomson and } \\
\text { Martinet } \\
\text { Oxford }\end{array}$ & 1986 & 383 & 8 & 4 & $\begin{array}{l}\text { "The definite article is used: When the object or group of } \\
\text { objects is unique...the equator, the stars.....Before a noun } \\
\text { made definite by the addition of a phrase or clause.....Before a } \\
\text { noun which by reason of locality can represent only one } \\
\text { particular thing: Ann is in the garden....Before superlatives... } \\
A \text { an is used: Before a singular noun which is countable } \\
\text { when it is mentioned for the first time and represents no } \\
\text { particular person or thing." }\end{array}$ \\
\hline $\begin{array}{l}\text { Interactions l: A } \\
\text { Communicative } \\
\text { Grammar }\end{array}$ & $\begin{array}{l}\text { Kirn and Jack } \\
\text { McGraw-Hill }\end{array}$ & 1985 & 295 & 0 & 0 & 0 \\
\hline $\begin{array}{l}\text { Interactions II: A } \\
\text { Communicative } \\
\text { Grammar } \\
\text { Second Edition } \\
\end{array}$ & $\begin{array}{l}\text { Werner and Church } \\
\text { McGraw-Hill }\end{array}$ & 1990 & 363 & 5 & 0 & $\begin{array}{l}\text { "The has specific uses with proper nouns, especially with } \\
\text { geographical locations. Because proper nouns identify } \\
\text { specific places, the is often used. There are few exceptions } \\
\text { to the rules. Study the following chart...." }\end{array}$ \\
\hline $\begin{array}{l}\text { A Closer Look: } \\
\text { An ESOL Grammar } \\
\text { Worktext }\end{array}$ & $\begin{array}{l}\text { Walker } \\
\text { Addison-Wesley }\end{array}$ & 1984 & 200 & 26 & 0.25 & $\begin{array}{l}\text { "The definite article is used if the meaning of the noun is } \\
\text { restricted to a particular example." Other directions are for } \\
\text { occasional uses, e.g., "The is not used when discussing the } \\
\text { general purpose of a building." }\end{array}$ \\
\hline $\begin{array}{l}\text { Modern English: } \\
\text { Exercises for } \\
\text { Non-Native } \\
\text { Speakers }\end{array}$ & $\begin{array}{l}\text { Frank } \\
\text { Prentice-Hall } \\
\text { Regents }\end{array}$ & 1986 & 236 & 21 & 0.25 & $\begin{array}{l}\text { "The occurs with names for familiar persons or objects in the } \\
\text { home and the community. It is also used with names for } \\
\text { natural objects in the world and in the universe. In these uses, } \\
\text { the limits a noun to the one specimen we are familiar with or } \\
\text { that we have in mind, although other specimens in the class } \\
\text { may exist....Keep in mind that a refers to one unknown or } \\
\text { unspecified person or thing, and that it is generally not used } \\
\text { with noncountable noun." Other directions are for occasional } \\
\text { uses, e.g. , "the with 'ranking' adjectives; the with words } \\
\text { referring to historical events, government, etc." }\end{array}$ \\
\hline $\begin{array}{l}\text { Making Sense } \\
\text { in English }\end{array}$ & $\begin{array}{l}\text { Pierson and Vik } \\
\text { Addison-Wesley }\end{array}$ & 1987 & 292 & 5.5 & 0.5 & $\begin{array}{l}\text { "THE. The article the appears... when that noun is clearly } \\
\text { identified. The identification may be clear from the speaker's } \\
\text { physical environment. There is often only one of a certain } \\
\text { object in the speaker's environment. The identification may be } \\
\text { clear from information in a previous sentence. Use a an...in } \\
\text { front of a noun the first time that noun is mentioned. Use the } \\
\text { to refer to the same noun later. The identification may be clear } \\
\text { from information in the same sentence. } \\
\text { NOUNS WITH NO ARTICLES. To make general statements } \\
\text { about all members of a group, use a plural count noun or a non- } \\
\text { count noun with no article." }\end{array}$ \\
\hline
\end{tabular}




\begin{tabular}{|c|c|c|c|c|c|c|}
\hline $\begin{array}{l}\text { Modem American } \\
\text { English }\end{array}$ & $\begin{array}{l}\text { Dixson } \\
\text { Prentice-Hall } \\
\text { Regents }\end{array}$ & 1992 & 154 & 0 & 0 & 0 \\
\hline Gaining Ground & $\begin{array}{l}\text { Cake and } \\
\text { Rogerson } \\
\text { Newbury House }\end{array}$ & 1986 & 310 & 0 & 0 & 0 \\
\hline $\begin{array}{l}\text { Communicate } \\
\text { What You Mean: } \\
\text { Grammar for } \\
\text { High-Level ESL } \\
\text { Students }\end{array}$ & $\begin{array}{l}\text { Pollock } \\
\text { Prentice-Hall } \\
\text { Regents }\end{array}$ & 1982 & 293 & 0 & 0 & 0 \\
\hline Grammar in Use & $\begin{array}{l}\text { Murphy } \\
\text { Cambridge } \\
\text { University Press }\end{array}$ & 1989 & 267 & 7 & 1 & $\begin{array}{l}\text { "We use alan when the listener doesn't know which thing we } \\
\text { mean. We use the when it is clear which thing we mean. Tom } \\
\text { sat down on a chair (we don't know which chair). Tom sat down } \\
\text { on the chair nearest the door (we know which chair). [also, } \\
\text { first mention takes alan]." }\end{array}$ \\
\hline $\begin{array}{l}\text { Scenario: English } \\
\text { Grammar in Context } \\
\text { Book } 3\end{array}$ & $\begin{array}{l}\text { Kirn } \\
\text { Holt, Rinehart and } \\
\text { Winston }\end{array}$ & 1984 & 211 & 0 & 0 & 0 \\
\hline $\begin{array}{l}\text { Scenario: English } \\
\text { Grammar in Context } \\
\text { Book } 2\end{array}$ & $\begin{array}{l}\text { Kirn } \\
\text { Holt, Rinehart and } \\
\text { Winston }\end{array}$ & 1984 & 237 & 13 & 3 & $\begin{array}{l}\text { "A non-specific noun has no identification yet. The } \\
\text { speaker...or listener...doesn't know anything about it yet. At } \\
\text { the first mention of a noun, it is usually non-specific. } \\
\text { A specific noun has identification. Both speaker...and } \\
\text { listener... already know something about it: } 1 \text {. Sometimes a } \\
\text { gesture identifies a noun. } 2 \text {. Sometimes the identification is in } \\
\text { the previous sentence. 3. Sometimes the identification is in } \\
\text { the same sentence. } 4 \text {. Sometimes a noun needs no } \\
\text { identification because it is specific from the context. } 5 \text {. } \\
\text { Sometirnes a noun needs no identification because there is } \\
\text { only one of that noun in the context." }\end{array}$ \\
\hline $\begin{array}{l}\text { Getting Along: } \\
\text { English Grammar } \\
\text { and Writing Book I }\end{array}$ & $\begin{array}{l}\text { Brinton and } \\
\text { Neuman } \\
\text { Prentice-Hall }\end{array}$ & 1982 & 276 & 3.5 & 0.5 & $\begin{array}{l}\text { "Use...a/an ... When the noun is introduced or identified for the } \\
\text { first time.... Use...the... when both listener and speaker know } \\
\text { something about the noun." }\end{array}$ \\
\hline $\begin{array}{l}\text { Getting Along: } \\
\text { English Grammar } \\
\text { and Writing Book } 2\end{array}$ & $\begin{array}{l}\text { Brinton and } \\
\text { Neuman } \\
\text { Prentice-Hall }\end{array}$ & 1982 & 306 & 3 & 0 & 0 \\
\hline
\end{tabular}




\begin{tabular}{|c|c|c|c|c|c|c|}
\hline $\begin{array}{l}\text { Grammar } \\
\text { Dimensions-1 }\end{array}$ & $\begin{array}{l}\text { Badalamenti and } \\
\text { Henrer-Stanchina } \\
\text { Heinle and Heinle }\end{array}$ & 1993 & 331 & 9 & 5 & $\begin{array}{l}\text { "A Aan is followed by a non-specific noun (The noun is one of } \\
\text { many)...[and is] used to introduce a noun phrase... The is } \\
\text { followed by a specific noun (the noun is known to the listener or } \\
\text { reader)....[The is] used when the noun phrase has already } \\
\text { been mentioned." }\end{array}$ \\
\hline $\begin{array}{l}\text { Grammar } \\
\text { Dimensions-2 }\end{array}$ & $\begin{array}{l}\text { Riggenbach and } \\
\text { Samuda } \\
\text { Heinle and Heinle }\end{array}$ & 1993 & 323 & & & $\begin{array}{l}\text { "The is used when the listener knows what specific thing or } \\
\text { person the speaker is talking about. The speaker is thinking } \\
\text { "you know what I mean" when he or she use the. The speaker } \\
\text { thinks that the listener knows what she or he means in different } \\
\text { situations: when the noun has already been } \\
\text { mentioned=second mention... when a related noun has already } \\
\text { been mentioned=related second mention. We also use the } \\
\text { definite article the when the noun is unique...the place where } \\
\text { you are speaking makes it clear... there's only one of the thing } \\
\text { mentioned...a/an is used when the speaker first mentions a } \\
\text { thing or person. " }\end{array}$ \\
\hline $\begin{array}{l}\text { Grammar } \\
\text { Dimensions-3 }\end{array}$ & Heinle and Heinle & 1993 & & & & \\
\hline $\begin{array}{l}\text { Grammar } \\
\text { Dimensions-4 }\end{array}$ & \begin{tabular}{|l|} 
Frodesen and \\
Eyring \\
Heinle and Heinle \\
\end{tabular} & 1993 & 403 & 18 & 0 & \\
\hline $\begin{array}{l}\text { Refining Composition } \\
\text { Skills: Rhetoric and } \\
\text { Mannor for ESL } \\
\text { Students } \\
\text { 3rd Edition }\end{array}$ & $\begin{array}{l}\text { Smalley and Hank } \\
\text { Maxwell-MacMillan }\end{array}$ & 1990 & 496 & 17 & 5.5 & $\begin{array}{l}\text { "The most common use of the indefinite article... is to signal } \\
\text { an unspecified item... He wants a bicycle. Note that there is no } \\
\text { attempt to make the noun specific. The noun is indefinite. } \\
\text { The definite article the signals a specific or particular } \\
\text { person, place or thing. Nouns can be made specific in several } \\
\text { ways: 1)... when the noun is first mentioned, it is unspecified, } \\
\text { so the article a is used. 2) The noun has a modifying phrase } \\
\text { or clause...that identifies it as a specific item. 3) The situation } \\
\text { identifies the noun. When both writer and reader are familiar } \\
\text { with the item that is being referred to, the is used. Often there } \\
\text { is only one such item. 4)The noun is specific because it is } \\
\text { unique. 5)The use of superlatives, ranking adjectives, and } \\
\text { ordinal numbers makes a noun specific." }\end{array}$ \\
\hline
\end{tabular}




\begin{tabular}{|c|c|c|c|c|c|c|}
\hline $\begin{array}{l}\text { Three Little Words: } \\
\text { A Foreign Student's } \\
\text { Guide to English } \\
\text { Articles }\end{array}$ & $\begin{array}{l}\text { Claire } \\
\text { Delta Systems }\end{array}$ & 1988 & 62 & 62 & 2.5 & $\begin{array}{l}\text { "The word the points out a definite person, place or thing or } \\
\text { idea, or one that has been mentioned before.... Use the when } \\
\text { the listener or reader already knows which things you mean, or } \\
\text { when there is only one possible item you are speaking about. } \\
\text { Use the with things that are the only ones of their kind. (There } \\
\text { may be others in the same class of things, but we don't usually } \\
\text { think about them)... Use the definite article, the, when you want } \\
\text { to point something out and make it definite...Use the indefinite } \\
\text { article a(an), with singular nouns that are not defintie." }\end{array}$ \\
\hline
\end{tabular}


APPENDIX B

LIST OF ESL TEXTBOOKS

REVIEWED IN THIS STUDY 


\section{ESL TEXTBOOKS \\ REVIEWED IN THIS STUDY}

Azar, B. 1984. Basic English Grammar. Englewood Cliffs, New Jersey: Prentice-Hall.

Azar, B. 1989. Understanding and Using English Grammar. 2nd.ed., Englewood Cliffs, New Jersey: Prentice-Hall.

Badalamenti,V. and C. Henrer-Stanchina. 1993. Grammar Dimensions-1. Boston, Mass: Heinle and Heinle.

Brinton, D. and R. Neuman. 1982a. Getting Along: English Grammar and Writing Book I. Englewood Cliffs, New Jersey: Prentice-Hall.

Brinton, D. and R. Neuman. 1982b. Getting Along: English Grammar and Writing Book II. Englewood Cliffs, New Jersey: Prentice-Hall.

Cake, C. and H. Rogerson. 1986. Gaining Ground. Cambridge, Mass: Newbury House.

Chamot, A., et al. 1992. Perspectives 2000. Boston, Mass.: Heinle and Heinle.

Claire, E.1988. Three Little Words: A Foreign Student's Guide to English Articles. Dundee, Ill: Delta Systems.

Davis, P. 1987. English Structure in Focus: Book One. Cambridge, Mass: Newbury House.

DeFilippo J. and D. Mackey. 1987. Grammar Plus: A Basic Skills Course. Reading, Mass.: Addison-Wesley.

Dixson, R. 1992. Modern American English. Englewood Cliffs, New Jersey: Prentice-Hall Regents.

Eichler, M. 1981. Developing Basic Writing Skills in English as a Second Language. Pittsburgh: University of Pittsburgh Press.

Elbaum, S. 1986. Grammar in Context: Book Two. Glenview, I11.: Scott, Foresman. 
Elbaum, S. 1989. Grammar in Context: Book One. Glenview, Ill.: Scott, Foresman.

Frank, M. 1972. Modern English: A Practical Reference Guide. Englewood Cliffs, New Jersey: Prentice-Hall.

Frank, M. 1986a. Modern English: Exercises for Non-Native Speaker: Part II Sentences and Complex Structures. Englewood Cliffs, New Jersey: Prentice-Hall Regents.

Frank, M. 1986b. Modern English Exercises for Non-Native Speakers: Part I Parts of Speech, 2nd.ed., Englewood Cliffs, New Jersey: Prentice-Hall.

Feigenbaum, I. 1985. The Grammar Handbook. Oxford: Oxford University Press.

Fingado, G. and M. Jerome. 1982. English Alive: Grammar, Function and Setting. Boston, Mass.: Little, Brown and Company .

Friedmann, T. 1988. Skills in Sequence. New York: St. Martins.

Frodesen, J. and J. Eyring. 1993. Grammar Dimensions-4. Boston, Mass: Heinle and Heinle.

Holschuh, L. 1991a. The Elements of English Grammar I. New York: St. Martins.

Holschuh, L. 1991b. The Functions of English Grammar II. New York: St. Martins.

Kirn, E. 1984. Scenario: English Grammar in Context Book 3. Austin, Texas: Holt, Rinehart and Winston.

Kirn, E. 1989. A Competency-Based Grammar. New York: Random House.

Kirn, E.and D. Jack. 1985. Interactions I: A Communicative Grammar. New York: McGraw-Hill.

Lites, E. and J. Lehman. 1990. Visions: A Pre-Intermediate Grammar. Englewood Cliffs, New Jersey: Prentice-Hall Regents.

Murphy, R. 1989. Grammar in Use: Reference and Practice for Intermediate Students. Cambridge: Cambridge University Press. 
Pierson, R. and S. Vik. 1987. Making Sense in English: Intermediate Grammar in Context. Reading, Mass: Addison-Wesley.

Pollock, C. 1982. Communicate What You Mean: Grammar for High-Level ESL Students. Englewood Cliffs, New Jersey: Prentice-Hall Regents.

Raimes, A. 1987. Exploring Through Writing: A Process Approach to ESL Composition. New York: St. Martins.

Raimes, A. 1990. How English Works: A Grammar Handbook with Readings. New York: St. Martins.

Riggenbach, H. and V. Samuda. 1993. Grammar Dimensions-2. Boston, Mass: Heinle and Heinle.

Robinson, B. 1989. Focus: An ESL Grammar. New York: St. Martins.

Smalley, R. and M. Hank. 1990. Refining composiiton Skills: Rhetoric and Mannor for ESL Students 3rd.ed., Maxwell-MacMillan.

Steer, J. and K. Carlisi. 1991. The Advanced Grammar Book. Cambridge, Mass: Newbury House.

Thomson, A. and A. Marinet. 1986. A Practical English Grammar 4th ed, Oxford: Oxford University Press.

Walker, M. 1984. A Closer Look: An ESOL Grammar Worktext. Reading, Mass: Addison-Wesley.

Werner, P. and M. Church. 1990. Interactions II: $A$ Communicative Grammar, 2nd ed., New York:McGraw-Hill.

Thewlis, S. 1993. Grammar Dimensions-3. Boston, Mass: Heinle and Heinle. 